CONTRERAS, Lautaro. "La responsabilidad penal del fabricante por la infracción de sus deberes de vigilancia, advertencia y retirada".

Polít. crim. Vol. 10, № 19 (Julio 2015), Art. 9, pp. 266-296.

[http://www.politicacriminal.cl/Vol_10/n_19/Vol10N19A9.pdf]

\title{
La responsabilidad penal del fabricante por la infracción de sus deberes de vigilancia, advertencia y retirada.
}

\section{Penal liability of the manufacturer for infringing its duties of vigilance, warning and recall.}

\author{
Lautaro Contreras Chaimovich \\ Legum magister y doctor por la Albert-Ludwigs-Universität (Alemania). \\ Profesor asistente del Departamento de Ciencias Penales, Universidad de Chile. \\ lcontreras@derecho.uchile.cl
}

\section{Resumen}

El presente artículo tiene por objeto de estudio los deberes jurídicos de vigilancia, advertencia y retirada que pesan sobre el productor, cuya infracción puede acarrear responsabilidad penal. Se trata de un problema que se enmarca dentro de la denominada "responsabilidad penal por el producto", rama del Derecho Penal de la Empresa escasamente tratada en la doctrina chilena. Luego de proponer un fundamento material para los deberes que el Derecho impone al productor, se entregan orientaciones para concretar las obligaciones de este frente al descubrimiento de "riesgos de desarrollo", y se aborda el problema relativo a la imputación de responsabilidad penal al interior de la empresa por la infracción de los deberes de vigilancia, advertencia y retirada.

Palabras clave: Responsabilidad penal por el producto, deberes del fabricante, deberes de vigilancia, advertencia y retirada, riesgos de desarrollo, Derecho Penal, Derecho Penal de la Empresa.

\section{Zusammenfassung}

Der Gegenstand dieses Aufsatzes sind die Beobachtungs-, Warnungs- und Rückrufspflichten des Herstellers, deren Verstoß strafrechtliche Verantwortlichkeit begründen kann. Es handelt sich um ein Problem der strafrechtlicher Produkthaftung, das ein Fall des Unternehmensstrafrechts darstellt und von der chilenischen Literatur bislang nicht hinreichend geklärt worden ist. Der Verfasser beantwortet zunächst die Frage, auf welche normative Grundlagen die Rechtstpflichten des Produzenten stützten können. Sodann folgen Ausführungen $\mathrm{zu}$ der Rechtskonkretisierung gegenüber Entwicklungsrisiken. Darauf folgend wird hinterfragt, welche Unternehmensangehörigen für die Erfüllung der Produzentenpflichten verantwortlich sind.

Stichworte: strafrechtliche Produktveratwortung, Produzentenpflichten, Beobachtungs-, Warnungs- und Rückrufspflichten, Entwicklungsrisiken, Strafrecht, Unternehmensstrafrecht. 
CONTRERAS, Lautaro. "La responsabilidad penal del fabricante por la infracción de sus deberes de vigilancia, advertencia y retirada".

El presente artículo analiza los deberes jurídicos de vigilancia, advertencia y retirada que pesan sobre el productor, cuya infracción puede acarrear responsabilidad penal. Se trata de una materia que se enmarca dentro de la denominada "responsabilidad penal por el producto", esto es, la responsabilidad criminal por las afectaciones a la vida y salud de los consumidores causadas por la fabricación y puesta en el mercado de productos defectuosos. La tesis fundamental que se quiere plantear en este artículo es que la vigilancia de productos - llevada a cabo con la finalidad de descubrir sus defectos no reconocibles al momentos de introducirlos en el mercado-, la advertencia a los consumidores de tales defectos, así como la eventual retirada de los bienes, no sólo constituyen prácticas empresariales cada vez más extendidas en Chile $^{1}$, sino que representan conductas exigidas por el Derecho. La omisión de tales conductas pone en tela de juicio deberes que protegen bienes jurídicos fundamentales, haciéndose necesaria la intervención penal.

Comenzaremos con una breve introducción a nuestro tema, distinguiendo entre orden primario de conducta y orden secundario penal, así como enunciando la relación que existe entre ambos. Sólo de esa manera es posible entender por qué para la responsabilidad penal por el producto -así como para cualquier otra manifestación del Derecho Penal- resulta tan relevante el quebrantamiento de ciertas normas de conducta o deberes jurídicos. Luego, se intentará ilustrar a través del "caso del alimento enteral"2 algunas de las normas de conducta básicas que debe acatar cualquier fabricante de productos (infra 1). El artículo seguirá con un intento por dar un fundamento material a tales normas (infra 2), refiriéndonos a continuación a la prohibición de poner en el mercado productos peligrosos (infra 3). Los deberes jurídicos de vigilancia, advertencia y retirada merecerán un estudio detallado (infra 4), especialmente en lo relativo a la pregunta cuándo un fabricante está obligado a advertir de un defecto y cuándo, en cambio, tiene el deber de retirarlo. Al respecto, veremos cómo el principio de proporcionalidad puede constituir una valiosa orientación en la materia (infra 4.2.). Finalmente, se intentarán esbozar algunas pautas para resolver el problema de quiénes son los responsables de cumplir con los deberes de vigilancia, advertencia y retirada al interior de la organización empresarial (infra 5).

\section{Introducción}

Los problemas jurídicos que se pueden abordar en el contexto de la responsabilidad penal por el producto son complejos y de variada índole. Dentro de estos se encuentra, por

1 Sólo por vía ejemplar: en agosto del 2014 una empresa fabricante de hardware anunció el retiro de cables de cargadores defectuosos para computadores (cfr. http://www.biobiochile.cl/2014/08/28/advierten-a-usuariossobre-cables-de-cargadores-hp-y-compaq-6-millones-corren-riesgo-de-incendio.shtml [visitado el 03.09.2014]); en el mismo mes una empresa distribuidora de estufas a gas alertó sobre un problema que presentaban los reguladores de cilindro de un determinado modelo (cfr. http://www.sernac.cl/alerta-deseguridad-estufa-infraroja-thermax-modelo-minimax-con-reguladores-de-cilindro-no-certifica/ [visitado el 03.09.2014]) y otra empresa automotriz comunicó una alerta de seguridad debido a un eventual defecto en el cinturón de seguridad de un modelo de vehículo (cfr. http://www.cooperativa.cl/noticias/pais/consumidores/sernac/sernac-alerto-por-eventual-falla-encinturon-de-seguridad-de-chevrolet-traverse/2014-08-05/113254.html [visitado el 03.09.2014]).

${ }^{2}$ Sentencia del Tribunal de Juicio Oral en lo Penal de San Bernardo de 24.08.2012, RUC 0800102576-8, RIT $38-2011$. 
Polit. crim. Vol. 10, № 19 (Julio 2015), Art. 9, pp. 266-296.

[http://www.politicacriminal.cl/Vol_10/n_19/Vol10N19A9.pdf]

ejemplo, la cuestión de la causalidad entre la fabricación o puesta en el mercado del producto y las consecuencias que de ello resultaron para la vida o salud de los consumidores $^{3}$, el papel que pueden desempeñar las autorizaciones administrativas con que cuente la empresa como causa de atipicidad o de justificación ${ }^{4}$, la pregunta acerca de si el conocimiento de los peligros que conlleva el producto puede fundar dolo o tan sólo imprudencia $^{5}$, el rol del principio de confianza ${ }^{6}$ como criterio normativo para delimitar ámbitos de responsabilidad, o todos los problemas que pueden presentarse en materia de autoría y participación en el seno de una organización empresarial. Sin perjuicio de ello, se estima que un aspecto esencial de la responsabilidad penal por el producto lo constituye la fundamentación y concreción de los deberes jurídicos (= prohibiciones y mandatos) que un fabricante debe cumplir.

La importancia de fundar y determinar los deberes jurídicos del fabricante radica en que su infracción representa el requisito mínimo para sancionar penalmente la conducta de aquel ${ }^{7}$.

${ }^{3}$ En relación con la causalidad en la responsabilidad por el producto, se distingue entre una "causalidad general" y una "causalidad concreta". La "causalidad general" se ocupa de la pregunta de si entre el consumo del producto y los daños producidos a los bienes jurídicos de los consumidores existe una ley empírica, en el sentido de una aptitud abstracta del producto para dañar, confirmada con un alto grado de probabilidad estadística. El término "causalidad general" fue acuñado por KAUFMANN, a propósito del caso Contergan (véase KAUFMANN, Armin, "Tatbestandsmäßigkeit und Verursachung im Contergan-Verfahren Folgerungen für das geltende Recht und für die Gesetzgebung", JZ 1971, pp. 569-576, p. 572; sobre el término "causalidad general" véase también BOSCH, Nikolaus, Organisationsverschulden in Unternehmen, Baden-Baden: Nomos, 2002, p. 95 ss. y HILGENDORF, Eric, "Der gesetzmäßige Zusammenhang im Sinne der modernen Kausallehre", Jura 1995, pp. 514-522, p. 515; en el Derecho chileno HERNÁNDEZ, Héctor, "El problema de la causalidad general en el derecho penal chileno [con ocasión del art. 232 del Anteproyecto de Nuevo Código Penal]", Polít. crim. n ${ }^{\circ} 1$ [2006], A7, p. 1-33 en: http://www.politicacriminal.cl/n_01/pdf_01/a_7.pdf [visitado el 03.09.2014]). La "causalidad concreta", por su parte, exige verificar dos cuestiones diversas (cfr. en lo que sigue MAYER, Michael, Strafrechtliche Produktverantwortung bei Arzneimittelschäden - Ein Beitrag zur Abgrenzung der Verantwortungsbereiche im Arzneiwesen aus strafrechtlicher Sicht, Berlin: Springer, 2008, p. 165 s.). Primero, determinar si efectivamente el contacto con el producto fue el factor causal para desencadenar el resultado, sin que existan otros elementos que puedan explicar también los daños a la vida o salud (por ejemplo, una conducta descuidada del propio consumidor). Segundo, establecer qué conductas específicas al interior de la empresa (lo que supone necesariamente distinguir entre las actuaciones de los distintos miembros de la organización empresarial) fueron las que ocasionaron (en el sentido de la teoría de la equivalencia) las muertes o lesiones de las víctimas.

${ }^{4}$ Sobre el efecto en el injusto de las decisiones de la autoridad en materia de responsabilidad penal por el producto véase MAYER, Strafrechtliche Produktverantwortung, cit. nota ${ }^{\circ} 3$, pp. 327 y ss. con abundantes citas.

${ }^{5} \mathrm{Al}$ respecto EICHINGER, Harald, Die strafrechtliche Produkthaftung im deutschen im Vergleich zum angloamerikanischen Recht, Frankfurt am Main: Peter Lang, 1997, p. 269 ss.; HÖHFELD, Hendrik, Strafrechtliche Produktverantwortung und Zivilrecht, Berlin: Springer, 1999, pp. 163 y ss.; SCHMUCKER, Andrea, Die „Dogmatik“ einer strafrechtlichen Produktverantwortung, Frankfurt am Main: Peter Lang, 2001, p. 103 ss.

${ }^{6}$ Sobre esto en detalle ALEXANDER, Thorsten, Die strafrechtliche Verantwortlichkeit für die Wahrung der Verkehrssicherungspflichten in Unternehmen, Herbolzheim: Centaurus, 2005, pp. 103, 127 y ss., 218 y ss.; DOMEIER, Danja, Gesundheitsschutz und Lebensmittelstrafrecht, Frankfurt am Main: Peter Lang, 1999, pp. 92 y ss.; EICHINGER, Die strafrechtliche Produkthaftung, cit. nota n ${ }^{\circ}$ 5, pp. 124 y ss., 228 y ss., 235 y ss.

${ }^{7}$ Fundamental al respecto FRISCH, Wolfgang, Vorsatz und Risiko Grundfragen des tatbestandsmäßigen Verhaltens und des Vorsatzes - Zugleich ein Beitrag zur Behandlung außertatbestandlicher Möglichkeitsvorstelllungen, Köln: Carl Heymanns, 1983, p.59 s.; FRISCH, Wolfgang, 
CONTRERAS, Lautaro. "La responsabilidad penal del fabricante por la infracción de sus deberes de vigilancia, advertencia y retirada".

Ello rige independientemente de la naturaleza del delito aplicable a los casos de responsabilidad penal por el producto, es decir, ya sea que nos encontremos frente a delitos de acción, de omisión, dolosos, culposos, de lesión o de peligro ${ }^{8}$. La reacción estatal a través de la imposición de una pena exige siempre la transgresión de una prohibición o mandato por parte del fabricante ${ }^{9}$.

Los deberes jurídicos del fabricante se hallan en el denominado "orden primario" u "orden de conducta", esto es, en aquella porción del ordenamiento jurídico que contiene prohibiciones y mandatos referidos a la conducta humana. El orden primario exige de los ciudadanos conductas ajustadas a Derecho, indicándoles a través de la imposición de deberes qué acciones u omisiones son necesarias para la protección de bienes jurídicos. Junto a este orden primario se halla el denominado "orden secundario penal" $\mathrm{u}$ "orden sancionatorio penal", que se manifiesta en los distintos tipos penales. El orden secundario como frecuentemente se destaca- tiene por destinatario fundamental al juez ${ }^{10}$, señalándole bajo qué requisitos puede castigar la infracción a un deber jurídico con una determinada pena $^{11}$. La finalidad inmediata de este orden secundario es proteger la vigencia de los

Verwaltungsakzessorietät und Tatbestandsverständnis im Umweltstrafrecht - Zum Verhältnis von Umweltverwaltungsrecht und Strafrecht und zur strafrechtlichen Relevanz behördlicher Genehmigungen, Heidelberg: Müller, 1993, p. 10; de acuerdo con él FREUND, Georg, Erfolgsdelikt und Unterlassen, Köln: Heymann, 1992, pp. 51 y ss., 167; FREUND, Georg, Strafrecht, Allgemeiner Teil, $2^{\text {a }}$ edición, Berlin: Springer, 2009, § 2, números marginales 5, 8 y 39; RENZIKOWSKI, Joachim, Restriktiver Täterbegriff und fahrlässige Beteiligung, Tübingen: Mohr Siebeck, 1997, p. 58.

${ }^{8}$ El que la sanción penal requiera la infracción de un deber jurídico se destaca normalmente sólo respecto del castigo de conductas imprudentes (donde se exige la infracción de un deber de cuidado) u omisivas (donde se requiere la transgresión de un deber de garante); sin embargo, este requisito debe predicarse respecto de cualquier clase de delito, en atención al carácter (siempre) accesorio del Derecho Penal. Sobre la naturaleza accesoria del Derecho Penal véase, entre otros, APPEL, Ivo, Verfassung und Strafe - Zu den verfassungsrechtlichen Grenzen staatlichen Strafens, Berlin: Duncker \& Humblot, 1998, pp. 431 y ss.; CONTRERAS, Lautaro, Normative Kriterien zur Bestimmung der Sorgfaltspfichten des Produzenten, Berlin: Duncker \& Humblot, 2012, pp. 18 y ss.; FREUND, Allgemeiner Teil, cit. nota ${ }^{\circ}$ 7, § 1, número marginal 12 ss.; WOHLERS, Wolfgang, Deliktstypen des Präventionsstrafrechts - Zur Dogmatik „moderner" Gefährdungsdelikte. Berlin: Duncker \& Humblot, 2000, p. 137; en el Derecho chileno véase ROJAS, Luis, "Accesoriedad del Derecho Penal", en: VAN WEEZEL, Alex (Editor), Humanizar y renovar el Derecho Penal, Estudios en memoria de Enrique Cury, Santiago: Legal Publishing, 2013, pp. 93-107, pp. 93 ss.

${ }^{9}$ Con todo, para la aplicación de un determinado tipo penal no basta con la infracción de cualquier deber de conducta. Por el contrario, es indispensable que la norma de conducta infringida pueda legitimarse en interés de la protección de aquel bien jurídico que el respectivo tipo penal pretende conservar (así FREUND, Allgemeiner Teil, cit. nota n ${ }^{\circ}$ 7, § 2, número marginal 9, 11; cfr. también REUS, Katharina, Das Recht in der Risikogesellschaft - Der Beitrag des Strafrechts zum Schutz vor modernen Produktgefahren, Berlin: Duncker \& Humblot, 2010, pp. 84 s.). Así, por ejemplo, para aplicar la sanción prevista en el art. 315 del Código Penal es indispensable que se infrinja un deber jurídico establecido para la protección de la salud pública. Luego, la transgresión de mandatos o prohibiciones que persigan garantizar la libre competencia, o que pretendan evitar fraudes patrimoniales en perjuicio del consumidor no pueden sancionarse criminalmente en virtud del art. 315 $\mathrm{CP}$.

${ }^{10}$ Acertadamente FRISCH, Vorsatz und Risiko, cit. nota ${ }^{\circ} 7$, pp. 62 y ss., 76 s., 347 s. El que los tipos penales están dirigidos fundamentalmente al juez lo pone de relieve también FREUND, Erfolgsdelikt, cit. nota $\mathrm{n}^{\circ}$ 7, p. 113 (pie de página 206, con ulteriores referencias) y KINDHÄUSER, Urs, Strafrecht, Allgemeiner Teil, $5^{\text {a }}$ edición, Baden-Baden: Nomos, 2011, § 2, número marginal 4.

${ }^{11}$ Cfr. FREUND, Allgemeiner Teil, cit. nota ${ }^{\circ} 7, \S 1$, número marginal 12; FRISCH, Vorsatz und Risiko, cit. nota $\mathrm{n}^{\circ}$ 7, p. 59; MÜNZBERG, Wolfgang, Verhalten und Erfolg als Grundlagen der Rechtswidrigkeit und Haftung, Frankfurt am Main: Klostermann, 1966, p. 68. 
Polit. crim. Vol. 10, № 19 (Julio 2015), Art. 9, pp. 266-296.

[http://www.politicacriminal.cl/Vol_10/n_19/Vol10N19A9.pdf]

mandatos y prohibiciones del orden de conducta, que es puesta en cuestión por quien ha quebrantado el deber jurídico $^{12}$; su finalidad mediata consiste en proteger aquellos bienes jurídicos que los mandatos y prohibiciones resguardan en forma directa ${ }^{13}$.

En tanto orden normativo secundario que busca asegurar la vigencia de determinados deberes jurídicos, el Derecho Penal sólo puede sancionar aquellas conductas que transgreden mandatos o prohibiciones y que, en consecuencia, son jurídicamente desaprobadas $^{14}$. Castigar conductas permitidas por el orden normativo primario, es decir, conductas que forman parte de la libertad general de actuación ${ }^{15}$ o de otro tipo de libertad garantizada constitucionalmente ${ }^{16}$, no sólo es irracional (las conductas permitidas no merecen un reproche; por el contrario, deben ser confirmadas), sino que, además, resulta ilegítimo en el contexto de la función preventivo general positiva que frecuentemente se asigna al Derecho Penal ${ }^{17}$.

El juicio de desaprobación jurídica de la conducta del fabricante -indispensable para la aplicación de cualquier tipo penal a un caso de responsabilidad por el producto- requiere confrontar la conducta realizada efectivamente por el fabricante con aquella mandada o prohibida por el Derecho ${ }^{18}$. Sólo si el productor se ha apartado de lo que el Derecho -en forma de deberes jurídicos- le exige para la mantención de la vida y salud del consumidor, estaremos frente a una conducta no tolerada jurídicamente.

${ }^{12}$ FRISCH, Vorsatz und Risiko, cit. nota $\mathrm{n}^{\circ} 7$, p. 48; de acuerdo con él FREUND, Allgemeiner Teil, cit. nota $\mathrm{n}^{\circ} 7, \S 1$, número marginal 12; KREMER-BAX, Alexandra, Das personale Verhaltensunrecht der Fahrlässigkeitstat - Zur Individualisierung des Bewertungsgegenstands, Frankfurt am Main: Peter Lang, 1999, p. 26.

${ }^{13}$ En este sentido APPEL, Verfassung, cit. nota $\mathrm{n}^{\circ}$ 8, pp. 452 y ss., 463; DOMEIER, Gesundheitsschutz, cit. nota $^{\circ}$ 6, p. 212; FREUND, Allgemeiner Teil, cit. nota ${ }^{\circ} 7$, § 1, número marginal 23; FRISCH, Wolfgang, Tatbestandsmäßiges Verhalten und Zurechnung des Erfolgs, Heidelberg: Müller, 1988, p. 516; MÜNZBERG, Verhalten und Erfolg, cit. nota ${ }^{\circ} 11$, p. 54; VOGEL, Joachim, "Verbraucherschutz durch strafrechtliche Produkthaftung - Kriminologische und funktionale Aspekte", GA 1990, pp. 241-264, p. 259.

${ }^{14}$ Así FRISCH, Tatbestandsmäßiges Verhalten, cit. nota ${ }^{\circ} 13$, p. 112 s.; de acuerdo con él FREUND, Erfolgsdelikt, cit. nota $\mathrm{n}^{\circ}$ 7, p. 51.

${ }^{15}$ Entendida esta como un derecho de actuación matriz y residual, que protege las manifestaciones de la libertad no aseguradas específicamente por los demás derechos constitucionales y que está consagrada en el art. 19 N. ${ }^{\circ}$ inc. $1^{\circ}$ de la Constitución (véase NOGUEIRA, Humberto, "La libertad personal y las dos caras de Jano en el ordenamiento jurídico chileno", Revista de Derecho, Vol. XIII [2002], pp. 161-186, p. 162).

${ }^{16}$ Detalladamente acerca de los derechos fundamentales del fabricante que se ven restringidos a través de las normas de conducta que garantizan la seguridad de productos HUFEN, Friedhelm, Verfassungsrechtliche Maßstäbe und Grenzen lebensmittel-strafrechtlicher Verantwortung - Zur Bestimmtheit, Differenziertheit und Verhältnismäßigkeit berufsregelnder Risikoverteilung, Baden-Baden: Nomos, 1987, pp. 87 y ss.

${ }^{17}$ En este sentido FRISCH, Verwaltungsakzessorietät, cit. nota n ${ }^{\circ}$ 7, p. 10.

${ }^{18}$ Este juicio de desaprobación jurídica no es exclusivo del Derecho Penal. También el Derecho Civil de la responsabilidad por el producto (;siempre que no se perfile como un régimen de responsabilidad estricta!) requiere la infracción de un deber de cuidado para que se imponga una indemnización de perjuicios (cfr. BARROS, Enrique, Tratado de responsabilidad extracontractual, Santiago de Chile: Editorial Jurídica de Chile, 2013, p. 750). Pero además, los deberes de conducta para la protección de la vida y salud que debe cumplir el fabricante para evitar una sanción penal son (en lo esencial) los mismos que debe acatar para no ser responsable civilmente por los daños a esos bienes jurídicos. Independientemente de cuál sea la reacción estatal frente a la infracción de tales deberes (en forma de sanción civil o penal), en el plano de las normas de conducta siempre nos encontramos frente al mismo problema: cómo conciliar de un modo razonable la libertad del fabricante con la libertad y los bienes jurídicos del consumidor. 
CONTRERAS, Lautaro. "La responsabilidad penal del fabricante por la infracción de sus deberes de vigilancia, advertencia y retirada".

\section{Los deberes jurídicos infringidos en el "caso del alimento enteral".}

En esta sección nos detendremos en el "caso del alimento enteral", que representó un hito indiscutible en materia de responsabilidad penal por el producto en Chile. Su análisis busca ilustrar algunas de las normas de conducta básicas que el Derecho impone a cualquier fabricante, y demostrar que la retirada de productos defectuosos ya no es un problema ajeno a la práctica jurisprudencial de nuestro país.

Antes de identificar los deberes jurídicos infringidos por los acusados en el "caso del alimento enteral", conviene recordar los hechos que lo motivaron: en abril de 2007 el jefe de control de calidad y el encargado de producción de la empresa farmacéutica X solicitaron a una compañía brasileña una mezcla de minerales, para la elaboración del alimento enteral "ADN", que la empresa X fabricaba y distribuía, especificando por error "cloruro de potasio al 1\%", en circunstancias que la fórmula del alimento exigía una concentración al 100\%. La mezcla importada de Brasil fue utilizada entre los meses de junio y noviembre de 2007 para la fabricación de 83 lotes de alimento, que sumaron cerca de 270.000 unidades defectuosas. Con posterioridad a noviembre de 2007, y luego de que la empresa farmacéutica descubriera el error de fabricación, los ejecutivos de la misma no advirtieron a los consumidores del peligro para la salud que el producto conllevaba ni lo retiraron inmediatamente del mercado. Asimismo, ordenaron agregar mayores dosis de potasio al alimento enteral, pero sin llegar a satisfacer los estándares exigidos por la fórmula del mismo; posteriormente, vendieron y distribuyeron masivamente el producto.

El alimento enteral "ADN" -suministrado a través de una sonda dirigida al tubo digestivoservía para que pacientes incapacitados de ingerir alimentos de un modo normal recibieran los diferentes nutrientes que necesitaba el organismo. Como el producto contenía dosis de potasio absolutamente inferiores a las requeridas, los consumidores comenzaron a sufrir trastornos severos en el equilibrio hidroelectrolítico del cuerpo (síndrome denominado "hipocalemia"). A raíz de ello, numerosas personas sufrieron afectaciones en su salud y varias murieron.

Ahora bien, ¿qué deberes jurídicos infringieron los responsables de las muertes y lesiones de los consumidores? Necesariamente hay que distinguir entre dos dimensiones temporales: hasta y después de noviembre del año 2007. Así, en lo tocante a las actuaciones desplegadas hasta noviembre de ese año, es posible identificar, a los menos, dos deberes infrigidos. En primer lugar, el deber jurídico del jefe de control de calidad de la empresa, así como del jefe de producción, en orden a informar correctamente la fórmula al proveedor brasileño ${ }^{19}$. Los riesgos para la vida y salud de los consumidores, provenientes de los posibles errores de comunicación entre quienes intervienen en el proceso de fabricación de un bien de consumo, son del todo previsibles. Tales peligros pueden aumentar si es que como ocurrió en este caso- son varias las empresas involucradas en dicho proceso. Los riesgos vinculados con los errores de comunicación hacían necesario que los encargados del

\footnotetext{
${ }^{19}$ La infracción de este deber podría ser captada penalmente por los delitos de homicidio culposo, lesiones culposas (sin mayor problema: lesiones menores graves culposas, en atención a la redacción del art. 399, que no contiene un catálogo taxativo de acciones típicas) y por el delito culposo del art. 315 inc. $2^{\circ}$, en relación con el art. 317 inc. $2^{\circ}$, ambos del Código Penal.
} 
Polit. crim. Vol. 10, № 19 (Julio 2015), Art. 9, pp. 266-296.

[http://www.politicacriminal.cl/Vol_10/n_19/Vol10N19A9.pdf]

control de calidad y de la producción ejecutaran el pedido a la empresa brasileña ajustándose estrictamente a la fórmula del alimento enteral. En segundo lugar, es posible advertir la infracción de otro deber: la obligación - de parte de los directivos de la empresa con facultades para configurar el proceso productivo- de establecer mecanismos o procesos que evitaran los errores de comunicación ya aludidos ${ }^{20}$. Al respecto hubiera sido necesario ordenar, por ejemplo, que la fórmula del producto se contuviera en un archivo informático protegido frente a cambios accidentales, cuya corrección hubiera sido revisada previamente por varias personas, de tal modo que llegara a manos de los proveedores de materia prima exenta de cualquier error. Lo anterior, sin perjuicio de establecer la obligación de efectuar pruebas para analizar el contenido de la mezcla de minerales que llegaba desde Brasil, para así garantizar que se ajustara correctamente a la fórmula.

En cuanto a las conductas desplegadas por los acusados luego de que el defecto de fabricación resultara evidente en noviembre del 2007, los directivos de la empresa infringieron la prohibición de seguir fabricando y comercializando el producto con niveles de potasio inferiores a los que exigía la fórmula. Pero además, violaron su obligación de advertir a los consumidores de que se encontraban en el mercado partidas defectuosas del alimento, así como su deber jurídico de retirar esos bienes del mercado.

Hasta donde se alcanza a ver, el "caso del alimento enteral" fue el primero en Chile en que se intentó hacer efectiva la responsabilidad penal del fabricante por la infracción de sus deberes de advertencia y retirada ${ }^{21}$. Es probable que no sea el último caso donde ello ocurra y que el riesgo de persecución criminal de los ejecutivos de empresas productoras, que omitan advertir de los peligros de sus productos o que no los retiren oportunamente del mercado, no decaiga en el futuro.

En los casos emblemáticos de la responsabilidad penal por el producto del Derecho alemán $^{22}$ el reproche que se hizo a los respectivos acusados fue justamente el de no haber advertido oportunamente a los consumidores acerca del peligro del producto -el que sólo

${ }^{20}$ La infracción de este deber también podría ser castigada por la vía de los tipos penales de homicidio culposo, lesiones menos graves culposas y el delito culposo del art. 315 inc. $2^{\circ}$, en relación con el art. 317 inc. $2^{\circ}$, ambos del Código Penal.

${ }^{21}$ Efectivamente, en la acusación del Ministerio Público se reprochó a los acusados el haber mantenido en circulación el producto defectuoso, sin advertir a centros hospitalarios, farmacias o clientes, ni tampoco informar a las autoridades de salud de los riesgos del alimento enteral (véase la exposición de los hechos de la acusación en el considerando segundo de la sentencia de del Tribunal de Juicio Oral en lo Penal de San Bernardo de 24.08.2012, RUC 0800102576-8, RIT 38-2011). El Tribunal de Juicio Oral en lo Penal de San Bernardo tuvo por probadas tales conductas omisivas (véase considerando $15^{\circ}$ de la sentencia), pero, incomprensiblemente, las sancionó por la vía del delito de acción del inciso segundo del art. 315 del Código Penal. Sobre el carácter omisivo de la conducta de no retirar un producto del mercado o de no alertar de sus defectos, y los tipos penales aplicables véase infra 4.3 .

${ }^{22}$ Casos Contergan (resolución del Tribunal Estadual de Aachen, JZ 1971, pp. 507 ss.), Monza-Steel (sentencia del Tribunal Estadual de München II, en: SCHMIDT-SALZER, Joachim, Entscheidungssammlung Produkthaftung, Bd. IV: Mit einer Einführung und Urteilsanmerkungen, Strafrechtliche Entscheidungen, Gesamtregister Bd. I-IV, Berlin: Schweitzer 1982, Nr. IV. 28, pp. 296 y ss.), Mandelbienenstich (sentencia del Tribunal Supremo Federal alemán, NStE, Nr. 5 zu $§ 223$ StGB [Mandelbienenstich], sin número de página), Lederspray (sentencia del Tribunal Supremo Federal alemán, BGHSt 37, pp. 106 y ss.) y Holzschutzmittel (sentencia del Tribunal Supremo Federal alemán, BGHSt 41, pp. 206 y ss.). 
CONTRERAS, Lautaro. "La responsabilidad penal del fabricante por la infracción de sus deberes de vigilancia, advertencia y retirada".

puedo ser reconocido después de haberlo puesto en el mercado- o de no haberlo retirado. Si se tiene en consideración que lo habitual es que el fabricante parta de la base de que el bien de consumo que acaba de comercializar no representa ningún peligro para la salud, y que frecuentemente su peligrosidad se descubra sólo con posterioridad a la comercialización, queda en evidencia la enorme importancia práctica de los deberes de advertencia y retirada en materia de responsabilidad por el producto.

\section{Fundamento normativo de los deberes jurídicos del fabricante.}

Antes de examinar los pormenores de los deberes de vigilancia, advertencia y retirada, resulta necesario abordar brevemente el fundamento normativo de los deberes jurídicos de todo fabricante. Tal fundamento resulta especialmente importante porque como los deberes del fabricante no siempre están positivizados ${ }^{23}$, o lo están pero sólo respecto de clases específica de $\operatorname{productos}^{24}$, podría pensarse que en aquellos ámbitos de riesgo donde no existen reglas jurídicas positivizadas que establezcan deberes de reducción de peligros, el fabricante puede ejercer su libertad sin restricción alguna. Sin embargo, de la falta de un programa de reducción de riesgos pre-penal no siempre se puede desprender una aprobación jurídica de la correspondiente creación de riesgo ${ }^{25}$. La falta de tal programa sólo trae implícito que el ordenamiento jurídico reconoce al fabricante, en el respectivo ámbito de riesgo, una amplia libertad para organizar su empresa de la manera a su juicio más eficiente, contratar con los proveedores más baratos y que le ofrezcan mayor confianza, comprar la maquinaria que estime pertinente, producir los bienes que él considere tendrán éxito comercial, etc. Con todo, tal uso de la libertad (general de actuación, de trabajo, a desarrollar actividades económicas, etc.) tiene límites impuestos por consideraciones de carácter material.

Cualquier planteamiento relativo al fundamento de los deberes del productor tiene que partir de la siguiente premisa: ningún sujeto de Derecho puede ejercer su libertad sin

\footnotetext{
${ }^{23}$ Como afirma correctamente Puppe, las normas de conducta que rigen para las distintas situaciones en que se puede encontrar un sujeto, y cuya transgresión funda un riesgo desaprobado, no siempre están positivizadas. Ello resulta lógico si se tiene presente la multiplicidad de situaciones de riesgos para bienes jurídicos que pueden presentarse en la vida diaria. Exigir al legislador un catálogo exhaustivo de normas de reducción de peligros es impracticable (piénsese, por ejemplo, en la eventual positivización de todas las normas de conducta que los padres deben observar para la protección de la vida y salud de sus hijos pequeños). Por eso, muchas veces corresponde al propio ciudadano concretar las reglas de cuidado que deben regir para la situación concreta en que se encuentra (PUPPE, Ingeborg, "Vorbemerkungen zu $\S \S 13 \mathrm{ff}$ ", en: KINDHÄUSER, Urs; NEUMANN, Ulfrid; PAEFFGEN, Hans-Ullrich [Editores], Nomos Kommentar, Strafgesetzbuch, Tomo 1, 4a edición, Baden-Baden: Nomos, 2013, número marginal 155; en un sentido similar REUS, Das Recht in der Risikogesellschaft, cit. nota $\mathrm{n}^{\circ}$ 9, p. 85).

${ }^{24}$ Así por ejemplo, el artículo 218 del Reglamento del sistema nacional de control de los productos farmacéuticos de uso humano (Decreto 3 del Ministerio de Salud, publicado en el Diario Oficial el 25 de junio del 2011) prevé expresamente un deber de vigilancia respecto de medicamentos; el Reglamento sobre seguridad de los juguetes (Decreto 114 del Ministerio de Salud, publicado en el Diario Oficial el 17 de junio del 2005), en cambio, no contiene tal obligación de vigilancia para esa clase de bienes de consumo.

${ }^{25}$ Piénsese en la ausencia de reglas pre-penales detalladas que establezcan reglas de reducción de determinados riesgos en la actividad médica. Tal ausencia no puede significar en caso alguno que el Derecho apruebe todos los riesgos (para la vida y salud del paciente) que el médico cree en el ejercicio de su profesión.
} 
Polit. crim. Vol. 10, № 19 (Julio 2015), Art. 9, pp. 266-296.

[http://www.politicacriminal.cl/Vol_10/n_19/Vol10N19A9.pdf]

consideración a los derechos o bienes jurídicos de los otros ${ }^{26}-\mathrm{Y}$ es que si tuviera lugar una vulneración generalizada de tales derechos o bienes, se destruirían las bases de existencia misma del sistema social ${ }^{27}$. Pero además, la única forma de maximizar la libertad de los individuos es garantizar que los demás no dañarán los derechos o bienes de aquellos ${ }^{28}$. La ausencia de expectativas normativas en este sentido afectaría el ejercicio de los derechos de un modo insoportable; piénsese, por ejemplo, en cómo se vería afectada la libertad ambulatoria si los participantes en el tráfico rodado tuvieran la incertidumbre permanente acerca de la creación o no de riesgos intolerables por parte de los otros. Es por ello que la obligación de ejercer la libertad de actuación sin afectar los derechos o bienes de los demás, debe ser el requisito inmanente de cualquier reconocimiento por parte del orden jurídico de tal libertad ${ }^{29}$.

En vista de lo anterior algo resulta evidente: el fabricante sólo puede ejercer su libertad bajo la condición de no poner en peligro la vida y salud de los consumidores cuando estos utilicen de un modo razonable sus productos. Cualquier persona en tanto potencial consumidor -también un fabricante en su calidad de potencial consumidor de productos- se declararía conforme con esa condición para el ejercicio de la libertad ${ }^{30}$.

Pero el deber jurídico que pesa sobre el fabricante en orden a no afectar los intereses de los consumidores también halla su legitimación en las expectativas propias de estos. Los consumidores esperan productos que no les dañen en caso de ser utilizados de un modo razonable, bajo ese supuesto - precisamente- los adquieren y utilizan. En caso de que no se puedan excluir absolutamente los peligros que surgen de la utilización razonable o normal del producto (por ejemplo, los riesgos propios de los efectos secundarios de un medicamento), los consumidores esperan que el productor se los informe con claridad y detalle. Dentro de las expectativas de los usuarios también se encuentra la de que el productor les advierta de los riesgos que han llegado a conocimiento de la empresa después de poner el producto en el mercado ${ }^{31}$. Todas estas expectativas permiten al consumidor dejar a un lado una serie de preocupaciones y cuidados, que son asumidos por el productor, en quien se deposita una determinada confianza. Ello no solo optimiza el ejercicio de la libertad del consumidor, sino que además fomenta (en favor del productor) la compra de

${ }^{26} \mathrm{Cfr}$. al respecto FRISCH, Wolfgang, "Notstandsregelungen als Ausdruck von Rechtsprinzipien”, en: PAEFFGEN, Hans-Ullrich et al (Editores), Strafrechtswissenschaft als Analyse und Konstruktion Festschrift für Ingeborg Puppe zum 70. Geburtstag, Berlin: Duncker \& Humblot, 2011, pp. 425-450, p. 428 s.; ZACZYK, Rainer, Das Unrecht der versuchten Tat, Berlin: Duncker \& Humblot, 1989, p. 212.

${ }^{27}$ Sobre la capacidad de la generalización de un argumento como criterio de justicia en el Derecho véase ZIPPELIUS, Reinhold, Rechtsphilosophie, $6^{\mathrm{a}}$ edición, München: C. H. Beck, 2011, p. 85.

${ }^{28}$ Cfr. ZACZYK, Das Unrecht, cit. nota n ${ }^{\circ}$ 26, p. 212.

${ }^{29}$ Así FRISCH, "Notstandsregelungen", cit. nota n 26, p. 429 con ulteriores referencias.

${ }^{30}$ Acerca de la capacidad de aceptación recíproca de una solución como método de concreción del Derecho aplicable véase FRISCH, Wolfgang, "Wesenszüge rechtswissenschaftlichen Arbeitens - am Beispiel und aus der Sicht des Strafrechts (Kommentar)", en: ENGEL, Christoph; SCHÖN, Wolfgang (Editores), Das Proprium der Rechtswissenschaft, Tübingen: Mohr Siebeck, 2007, pp. 156-184, p. 177; HABERMAS, Jürgen, Faktizität und Geltung - Beiträge zur Diskurstheorie des Rechts und des demokratischen Rechtsstaats, $2^{\mathrm{a}}$ edición, Frankfurt am Main: Suhrkamp, 1992, pp. 138 y ss.; RAWLS, John, Eine Theorie der Gerechtigkeit, Frankfurt am Main: Suhrkamp, 1975, pp. 81 y ss., 85, 158, 159 y ss.; ZIPPELIUS, Rechtsphilosophie, cit. nota $\mathrm{n}^{\circ} 27$, pp. 102, 121 y ss., 178 s.

${ }^{31}$ FRISCH, Tatbestandsmäßiges Verhalten, cit. nota ${ }^{\circ} 13$, p. 199. 
CONTRERAS, Lautaro. "La responsabilidad penal del fabricante por la infracción de sus deberes de vigilancia, advertencia y retirada".

bienes "dignos de confianza". El fabricante que quiere aprovechar las ventajas (fundamentalmente económicas) que las expectativas descritas traen consigo, debe cumplir con la respectiva "contraprestación", a saber: él no puede crear a través de la introducción de productos en el mercado riesgos jurídicamente desaprobados en perjuicio de la vida y salud del consumidor. Si él no está en condiciones de desarrollar su actividad sin afectar tales bienes jurídicos, simplemente no debe emprenderla ${ }^{32}$.

De la obligación fundamental del fabricante en orden a no poner en peligro la vida y salud de los consumidores surgen dos tipos de deberes jurídicos. Por una parte, sobre el fabricante pesa la prohibición de poner en el mercado productos peligrosos en caso de utilización racional o normal ${ }^{33}$. Por otra, el fabricante está obligado (con miras a identificar riesgos en su momento no reconocibles) a vigilar el producto a partir de su introducción en el mercado, a advertir de los posibles riesgos a los consumidores y a retirar el producto del mercado, en caso de ser necesario.

Ahora bien, resulta evidente que todo producto puede -dado el caso- representar un peligro para los bienes jurídicos del consumidor. Incluso un producto que a primera vista parece ser totalmente inocuo tiene la capacidad de dañar, si el consumidor lo utiliza de una manera irracional o que se aparte de su normal destino. Piénsese, por ejemplo, en la utilización de un medicamento con posterioridad a su fecha de caducidad, o en el empleo de un aparato eléctrico para una finalidad totalmente diversa a la que le asignó el fabricante. Pero todos los riesgos que surgen del empleo irracional de un producto, o de un uso que no correspondan a su normal destino, deben constituir riesgos permitidos o tolerados por el ordenamiento jurídico ${ }^{34}$. Normas de conducta que obligaran al fabricante a poner productos en el mercado que sean seguros incluso frente a una utilización negligente o disparatada constituirían restricciones insoportable de la libertad de acción, no sólo de los fabricantes, sino también de los propios consumidores. Y es que deberes jurídicos semejantes podrían ser imposibles de cumplir conforme al estado de la técnica (con lo que los consumidores se verían privados del respectivo producto), o disparar los costos $\mathrm{y}$, en consecuencia, el precio $^{35}$. Es claro que los consumidores no están interesados en tales normas de conducta. Por el contrario, su interés se dirige a productos que no representen un riesgo en caso de utilización racional o normal.

\footnotetext{
${ }^{32}$ Cfr. al respecto FREUND, Erfolgsdelikt, cit. nota $\mathrm{n}^{\circ}$ 7, p. 219; FREUND, Allgemeiner Teil, cit. nota $\mathrm{n}^{\circ} 7$, $\S 6$, número marginal 69.

${ }^{33}$ Cfr. por ejemplo el art. 5 del Reglamento sobre seguridad de los juguetes (Decreto 114 del Ministerio de Salud, publicado en el Diario Oficial el 17 de junio del 2005).

${ }^{34}$ En detalle sobre las distintas formas de uso de un producto de consumo y los límites del riesgo tolerado véase CONTRERAS, Normative Kriterien, cit. nota ${ }^{\circ} 8$, pp. 203 y ss.

${ }^{35}$ Piénsese en un deber jurídico que obligara a los fabricantes de secadores de pelo a poner en el mercado artefactos que jamás provocaran accidentes, incluso estando en contacto con el agua de una tina de baño. Tal deber no podría cumplirse de acuerdo al estado de la técnica o, de poder cumplirse, dispararía el precio de tal modo que los propios consumidores se verían privados de bienes de consumo en los que están interesados.
} 
Polít. crim. Vol. 10, № 19 (Julio 2015), Art. 9, pp. 266-296.

[http://www.politicacriminal.cl/Vol_10/n_19/Vol10N19A9.pdf]

\section{La prohibición de poner en el mercado productos peligrosos en caso de utilización racional o normal.}

La prohibición de poner en el mercado productos peligrosos en caso de utilización racional o normal se infringe si el producto contiene defectos de diseño, fabricación o instrucción ${ }^{36}$. Un producto adolece de un diseño defectuoso cuando la concepción del mismo no cumple con los estándares de calidad que garantizan su uso seguro ${ }^{37}$. El defecto de fabricación se presenta cuando - debido a una falla en la fase de producción- el bien no alcanza el nivel de seguridad que sí mostraba el diseño del producto ${ }^{38}$. Los defectos de instrucción, por su parte, se verifican cuando los productos carecen de las instrucciones necesarias para un uso seguro o bien cuando no se advierte al consumidor de ciertos peligros ${ }^{39}$. Al respecto se hace necesario precisar que en el caso del "alimento enteral" antes visto, el producto en cuestión no presentaba un fallo de diseño ni de instrucción, sino de fabricación. El diseño del producto estaba exento de fallas, pues su fórmula exigía (correctamente) una concentración de potasio al $100 \%$. Tampoco se presentó un problema de instrucción. Lo que hubo en este caso fue una divergencia entre el diseño y lo efectivamente fabricado, discrepancia causada por un descuido en un hito fundamental del proceso de elaboración del producto, a saber: el pedido a los proveedores brasileños de la mezcla de minerales ${ }^{40}$.

Para la evitación de defectos de diseño, fabricación o instrucción, el fabricante tiene el deber de ajustar su conducta especialmente a las normas pre-jurídicas (reglas técnicas) que

${ }^{36}$ La distinción entre los distintos defectos de que puede adolecer un producto no es baladí para el Derecho: sólo una correcta identificación del tipo de defecto en que se ha incurrido nos permite aclarar quién o quiénes al interior de la empresa eran los responsables de su evitación. Como la organización empresarial se rige por el principio de división del trabajo, la correcta identificación del defecto es fundamental para deslindar ámbitos de responsabilidad.

${ }^{37}$ Sobre los defectos de diseño véase FOERSTE, Ulrich, "§ 24. Verkehrspflichten im Bereich der Warenherstellung”, en: GRAF V. WESTPHALEN, Friedrich (Editor), Produkthaftungshandbuch, Tomo 1, $2^{\mathrm{a}}$ edición, München: C. H. Beck, 1997, número marginal 59; HAGER, Johannes, “§ 823”, en: J. von Staudingers Kommentar zum Bürgerlichen Gesetzbuch mit Einführungsgesetz und Nebengesetzen, Buch 2 Recht der Schuldverhältnisse $\$ \$ 823$ E-I, 824, 825 (Unerlaubte Handlungen 1 - Teilband 2), Berlin: Sellier de Gruyter, 2009, número marginal F 12. Un ejemplo de defecto de diseño se puede hallar en el caso Contergan (Tribunal Estadual de Aachen, JZ 1971, pp. 507 y ss.). Allí se comercializó un medicamento que contenía talidomina, cuyo uso traía consigo graves efectos teratogénicos no conocidos oportunamente por la empresa farmacéutica.

${ }^{38}$ Así FOERSTE, “\$ 24. Verkehrspflichten”, cit. nota n³7, número marginal 131.

${ }^{39}$ En detalle sobre los defectos de instrucción véase HAGER, "\$ 823", cit. nota n 37, número marginal F 14; SALVADOR, Pablo; RAMOS, Sonia, "Capítulo IV. Defectos de producto", en: SALVADOR, Pablo; GÓMEZ, Fernando (Editores), Tratado de responsabilidad civil del fabricante, Cizur Menor: Aranzadi, 2008, pp. 135-219, p. 189; SPINDLER, Gerald, “§ 823”, en: BAMBERGER, Heinz Georg; ROTH, Herbert (Editores), Beck'scher Online-Kommentar BGB, 20ª Edición, München: C. H. Beck, 2011, número marginal 502. El orden primario prevé expresamente un deber de evitar defectos de instrucción para toda clase de productos (art. 45 inc. $1^{\circ}$ de la Ley N. ${ }^{\circ} 19.496$ sobre protección de los derechos de los consumidores).

${ }^{40}$ Calificar con precisión de qué clase de defecto adolecía el alimento enteral (de fabricación o de rotulado) no es un asunto baladí, porque sólo una correcta identificación del tipo de defecto nos permite aclarar cuáles fueron los deberes del fabricante infringidos en el caso concreto y, consecuentemente -y en atención a que lo normal es que exista al interior de toda empresa productora división del trabajo-, quién o quiénes al interior de la empresa debían cumplirlos. Sobre la distribución de deberes al interior de la organización véase infra 5. 
CONTRERAS, Lautaro. "La responsabilidad penal del fabricante por la infracción de sus deberes de vigilancia, advertencia y retirada".

rijan el respectivo ámbito productivo ${ }^{41}$. Se trata de las más variadas "reglas del arte", "prescripciones", "normas", "directrices" o "recomendaciones" desarrolladas por asociaciones de profesionales o técnicos en el ámbito del diseño, fabricación e instrucción de los más variados productos, y que persiguen la limitación o reducción de riesgos para los bienes jurídicos del consumidor. Tales normas pre-jurídicas constituyen la manifestación de la experiencia acumulada en el respectivo sector productivo. Expresan un saber empírico aplicado e indicar la forma de proceder para dominar ciertos peligros ${ }^{42}$. En tal contexto, las normas pre-jurídicas juegan un rol esencial para fundar la previsibilidad de los resultados lesivos que puede desencadenar las conductas del fabricante ${ }^{43}$. En la medida que tales normas pre-jurídicas representen un compromiso normativo adecuado entre los intereses en la libertad y el mantenimiento de bienes jurídicos, su infracción o acatamiento por parte del fabricante tendrá consecuencias relevantes para responder la pregunta si los riesgos creados por este tienen el carácter de desaprobados o permitidos ${ }^{44}$. Las normas pre-jurídicas serán el reflejo de una ponderación adecuada entre los intereses en la libertad y el mantenimiento de bienes cuando su cumplimiento no dispare los costos de producción, no afecte la utilidad del producto y reduzca el riesgo de tal modo que un consumidor razonable no dejaría de emplear el bien de consumo para proteger su vida y salud ${ }^{45}$. De tal modo, los riesgos que surjan de la conducta del fabricante que se desvíen de lo que las normas pre-jurídicas adecuadas prescriben para la evitación de defectos de diseño, fabricación o instrucción

${ }^{41}$ Fundamental para la distinción entre normas pre-penales y pre-jurídicas en el ámbito del Derecho Penal FRISCH, Tatbestandsmäßiges Verhalten, cit. nota $\mathrm{n}{ }^{\circ} 13$, pp. 90 ss. Ambas clases de normas contienen reglas para reducir o excluir los peligros conectados a determinadas conductas. Sin embargo, mientras las normas pre-penales (contenidas en leyes, reglamentos dictados en virtud de la potestad reglamentaria del Presidente de la República, etc.) son establecidas por las instancias estatales competentes, las normas pre-jurídicas (reglas técnicas) no pertenecen al orden jurídico objetivo y no contienen mandatos o prohibiciones vinculantes con carácter general (véase al respecto CONTRERAS, Normative Kriterien, cit. nota $\mathrm{n}^{\circ} 8$, $\mathrm{p}$. 144).

${ }^{42}$ Ver CONTRERAS, Normative Kriterien, cit. nota ${ }^{\circ}$ 8, p. 145.

${ }^{43}$ En tal sentido FRISCH, Tatbestandsmäßiges Verhalten, cit. nota ${ }^{\circ} 13$, p. 103. Con todo, la previsibilidad del acaecimiento del resultado, conforme a la respectiva norma pre-jurídica, no permite fundar por sí sola la tipicidad de la conducta del fabricante (en el sentido de los delitos de homicidio o lesiones corporales). Tal previsibilidad sólo nos indica que la conducta es peligrosa. Que la respectiva creación de riesgo del fabricante (que se ha apartado de la norma pre-penal) deba ser desaprobada requiere de valoraciones normativas adicionales. Para la desaprobación jurídica de la conducta del fabricante no es decisivo que el efecto dañoso de un producto sea fácticamente previsible, sino que ese efecto deba ser evitado por el Derecho sobre la base de una adecuada ponderación de intereses. Al respecto CONTRERAS, Normative Kriterien, cit. nota $\mathrm{n}^{\circ} 8, \mathrm{p}$. 146 con ulteriores referencias.

${ }^{44}$ Expresamente FRISCH, Tatbestandsmäßiges Verhalten, cit. nota ${ }^{\circ} 13$, p. 106.

${ }^{45} \mathrm{La}$ adecuación de las normas pre-jurídicas que debe cumplir un fabricante ha de analizarse a la luz de los propios intereses del consumidor, cuyos bienes jurídicos son los que se pretenden proteger a través de tales normas. Es por eso que las normas pre-jurídicas no sólo deben reducir o eliminar aquellos peligros a los que un consumidor sensato no se expondría, sino que, además, su cumplimiento no debe significar un incremento desmedido de los costos ( $i y$ precios!). Toda norma técnica cuyo cumplimiento los aumentara excesivamente podría acarrear que el consumidor se vería privado de productos a cuyo acceso él mismo está interesado, con la consiguiente pérdida en el ejercicio de su libertad. Pero además -y ello resulta totalmente lógico- el cumplimiento de una norma técnica no debe menoscabar la función característica del producto, que es la persiguen los propios consumidores. Así, por ejemplo, una norma pre-jurídica no podría disminuir el riesgo de cortes en las manos provenientes de cuchillos o tijeras si eso conlleva menoscabar la propia funcionalidad de tales utensilios. Sobre los criterios valorativos para enjuiciar la adecuación de una norma técnica véase CONTRERAS, Normative Kriterien, cit. nota $n^{\circ} 8$, pp. 210 y ss. 
Polit. crim. Vol. 10, № 19 (Julio 2015), Art. 9, pp. 266-296.

[http://www.politicacriminal.cl/Vol_10/n_19/Vol10N19A9.pdf]

representarán, normalmente, riesgos jurídicamente desaprobados ${ }^{46}$. Por el contrario, aquellos peligros que puedan subsistir aun cumpliendo con los respectivos deberes de diseño, fabricación o instrucción, contenidos en normas pre-jurídicas que puedan considerarse como adecuadas, constituirán riesgos jurídicamente permitidos o tolerados.

Ahora bien, la transgresión de la prohibición de poner en el mercado productos peligrosos por defectos de diseño, fabricación o instrucción, debe ser tratada conforme a los principios que rigen para los delitos de acción. Pues aquí el injusto decisivo no debe hallarse en la omisión del cumplimiento de un deber jurídico específico, sino en una conducta positiva que no cumple con determinados requisitos y que, por consiguiente, es contraria a una prohibición, a saber: poner en el mercado un producto que no cumple ciertas condiciones mínimas de seguridad ${ }^{47}$. Tal conducta positiva contraria a Derecho podría castigarse penalmente en el marco de los delitos de homicidio (art. 391 N² del Código Penal, "CP"), de lesiones (especialmente las previstas en los arts. 398 -primera modalidad típica-, 399 y $494 \mathrm{~N}^{\circ} 5$, todos del CP) ${ }^{48}$ y contra la salud pública (arts. 313d, 314, 315, todos del CP).

\section{Los deberes de vigilancia, advertencia y retirada del producto.}

\subsection{Los "riesgos de desarrollo" y la necesaria vigilancia, advertencia y retirada del producto.}

A pesar de la estricta observancia de la prohibición de comercializar productos peligrosos en caso de utilización racional, la conducta del fabricante puede constituir un factor causal para la afectación de los bienes jurídicos del consumidor. Ello ocurrirá cuando un fabricante diligente no reconozca los riesgos del producto al momento de ponerlo en el mercado, aun aplicando todo el cuidado exigido por el Derecho. Tal tipo de riesgos se denominan "riesgos de desarrollo" "49 La Ley N. 19.496 sobre protección de los derechos de los consumidores (cfr. artículo 47 inciso segundo) excluye la responsabilidad (civil) por tales riesgos, pues no es razonable que el fabricante esté obligado a impedir aquellos cursos peligrosos para los bienes jurídicos de los consumidores que no puedan reconocerse desde

${ }^{46}$ La infracción de la respectiva norma pre-jurídica no representará una creación de riesgo jurídicamente desaprobado cuando el fabricante alcance el mismo nivel de seguridad exigido por la norma a través de un procedimiento técnico distinto. En este sentido LENCKNER, Theodor, "Technische Normen und Fahrlässigkeit”, en: BOCKELMANN, Paul (Editor), Festschrift für Karl Engisch zum 70. Geburtstag, Frankfurt am Main: Klostermann, 1969, pp. 490-508, p. 502.

${ }^{47}$ Véase FRISCH, Tatbestandsmäßiges Verhalten, cit. nota ${ }^{\circ}{ }^{\circ} 13$, p. 201 (pie de página 172).

${ }^{48}$ Los delitos de mutilaciones de los arts. 395 y 396 del CP serán raramente aplicables a los casos de responsabilidad por el producto, toda vez que no será frecuente que el fabricante cercene una parte del cuerpo a través de la introducción en el mercado de un bien de consumo (sólo cabría pensar, por vía de ejemplo, en algún tipo de elemento del trabajo defectuoso -sierra, prensa, etc.- que provocara un grave accidente laboral, o en vehículos con fallas de diseño o fabricación causantes de accidentes donde resultaran personas mutiladas). Por su parte, la mención que se hace en el delito de lesiones graves del art. 397 CP a modos de comisión extremadamente restrictivos (herir, golpear o maltratar) hace difícil la posibilidad de castigar en virtud de este ilícito la conducta del fabricante consistente en introducir en el mercado productos defectuosos.

${ }^{49}$ Sobre los riesgos de desarrollo véase BODEWIG, Theo, Der Rückruf fehlerhafter Produkte - Eine Untersuchung der Rückrufpflichten und Rückrufansprüche nach dem Recht Deutschlands, der Europäischen Union und der USA, Tübingen: Mohr Siebeck, 1999, pp. 51, 59 y 107. En el Derecho chileno véase CORRAL, Hernán, Responsabilidad por productos defectuosos - Análisis y propuestas para el Derecho Civil y de Consumo en Chile, Santiago de Chile: Legal Publishing Chile, 2011, pp. 132, 238 y ss. 
CONTRERAS, Lautaro. "La responsabilidad penal del fabricante por la infracción de sus deberes de vigilancia, advertencia y retirada".

una perspectiva ex ante. Los riesgos de desarrollo están tolerados por el orden jurídico prepenal y, en consecuencia, no pueden fundamentar una responsabilidad criminal, en atención al carácter siempre accesorio del Derecho Penal ${ }^{50}$.

Ahora bien, aunque no sea posible justificar una responsabilidad del fabricante por los riesgos no identificables al momento de comercializar su producto, sus deberes jurídicos no cesan ahi ${ }^{51}$. Por el contrario, el fabricante está obligado, a partir de la comercialización del producto, a "vigilarlo" permanentemente, en relación a posibles riesgos ocultos, e informarse de las eventuales consecuencias perjudiciales que, para los intereses de los consumidores, la utilización del producto traiga consigo ${ }^{52}$. Este deber de vigilancia se hace cargo de la circunstancia de que, frecuentemente, pese a la realización de todas las pruebas y controles necesarios durante las etapas de desarrollo y fabricación de un bien de consumo, determinados riesgos sólo se manifiestan en la utilización diaria del mismo ${ }^{53}$. Piénsese, por ejemplo, en los efectos secundarios perjudiciales de ciertos medicamentos, que sólo se vuelven perceptibles después de su uso prolongado por los pacientes y que no han podido ser identificados ni siquiera a través de exhaustivos test en la etapa de desarrollo.

Junto con la prohibición de poner en el mercado productos peligrosos en caso de utilización racional, el mandato de vigilancia recién indicado representa la contrapartida lógica de la libertad que se le reconoce al productor en orden a obtener ventajas de una actividad riesgosa ${ }^{54}$. Quien pone en el mercado bienes potencialmente peligrosos es responsable por tal peligrosidad, aun cuando esta sólo se ponga en evidencia con posterioridad a la comercialización $^{55}$. La imposición de tal deber constituye por lo demás la repartición de cargas más justa entre fabricante y el consumidor, pues no parece razonable ni justo que aquel ejerza su libertad económica (obteniendo un provecho patrimonial de ello) y pretenda que sea el consumidor el competente para hacer frente a los riesgos de desarrollo que tal

\footnotetext{
${ }^{50}$ En tanto orden accesorio, el Derecho Penal sólo puede castigar conductas desaprobadas por el orden normativo primario. Por consiguiente, las conductas del fabricante que están toleradas por el Derecho Civil o el Derecho Administrativo no pueden estimarse nunca como penalmente relevantes (cfr. DANNECKER, Gerhard, "Fahrlässigkeit in formalen Organisationen", en: AMELUNG, Knut (Editor), Individuelle Verantwortung und Beteiligungsverhältnisse bei Straftaten in Bürokratischen Organisationen des Staates und der Gesellschaft, Sizheim: Pro-Universitate, 2000, pp. 209-237, p. 221).

${ }^{51}$ En este sentido BORER, Peter, Produktehaftung: Der Fehlerbegriff nach deutschem, amerikanischem und europäischem Recht, Bern: Haupt, 1986, p. 60; PFEIFER, Axel, Produktfehler oder Fehlverhalten des Produzenten - Das neue Produkthaftungsrecht in Deutschland, den USA und nach der EG-Richtlinie, Berlin: Duncker \& Humblot, 1987, p. 92; SPINDLER, “\$ 823”, cit. nota n³9, número marginal 510.

${ }^{52}$ Tribunal Supremo Federal alemán, BGHZ 80, 186, 191; BORER, Produktehaftung, cit. nota ${ }^{\circ}$ 51, p. 60; MICHALSKI, Lutz, "Produktbeobachtung und Rückrufpflicht des Produzenten”, BB 1998, pp. 961-966, p. 963; PFEIFER, Produktfehler, cit. nota $\mathrm{n}^{\circ}$ 51, p. 92.

${ }^{53}$ Así MAYER, Strafrechtliche Produktverantwortung, cit. nota n 3, p. 289; cfr. también HOLTERMANN, Christian, Neue Lösungsansätze zur strafrechtlichen Produkthaftung - Eine Untersuchung unter Heranziehung des Tatbestandes der gemeingefährlichen Vergiftung - \$314 Abs. 1 Nr. 2 StGB, Baden-Baden: Nomos, 2007, p. 38.

${ }^{54}$ Así FREUND, Georg, "Vorbem. zu den $\S \S 95$ ff. AMG”, en: JOECKS, Wolfgang; MIEBACH, Klaus (Editores), Münchener Kommentar zum Strafgesetzbuch, Tomo 5, München: C. H. Beck, 2007, número marginal 12; FREUND, Georg, Allgemeiner Teil, cit. nota $\mathrm{n}^{\circ}$ 7, § 6, número marginal 26.

${ }^{55}$ Cfr. FREUND, Georg, "Vorbem. zu den $§ \S 95$ ff. AMG”, cit. nota n 54, número marginal 12.
} 
Polit. crim. Vol. 10, № 19 (Julio 2015), Art. 9, pp. 266-296.

[http://www.politicacriminal.cl/Vol_10/n_19/Vol10N19A9.pdf]

ejercicio de la libertad conlleva ${ }^{56}$. Por lo demás, el fabricante cuenta con el conocimiento técnico y los medios materiales necesarios para identificar los riesgos ocultos del producto. Esta labor de indagación de peligros sobrepasa por completo la capacidad de un consumidor promedio.

El fabricante está obligado a vigilar el producto pasiva y activamente. Por una parte, debe verificar la efectividad de todos los reclamos que lleguen a la empresa y que digan relación con defectos del producto que puedan desencadenar afectaciones a los bienes del consumidor $^{57}$. Este deber de vigilancia pasiva está previsto expresamente en la legislación chilena sobre medicamentos ${ }^{58}$, lo que no implica que no rija respecto de otros productos de consumo $^{59}$. Por otra parte, el fabricante tiene la obligación de vigilar activamente los posibles defectos del producto, esto es, debe tomar la iniciativa para generar y valorar aquella información que le permita descubrir los riesgos del producto no reconocibles al momento de su introducción en el mercado ${ }^{60}$. Así, debe hacer un seguimiento de los reclamos en que se hayan visto involucradas empresas que comercialicen productos similares al suyo, está obligado a asistir a seminarios y congresos en que se expliquen los riesgos de los productos de la respectiva rama, debe estar suscrito a literatura técnica que le permita tomar conocimiento de tales riesgos, tiene que indagar en internet acerca de posibles defectos del producto, etc. ${ }^{61}$. El alcance del deber de vigilancia depende de la intensidad del riesgo del producto $^{62}$. Productos especialmente peligrosos para los bienes de los consumidores, en atención a su naturaleza o al público al que están destinados, como alimentos para recién nacidos, juguetes, instrumental y aparatos médicos, productos farmacéuticos, implementos para la seguridad en el trabajo, sustancias químicas, etc. exigen una vigilancia particularmente estricta. Lo mismo puede decirse de productos recientemente desarrollados, que no existían antes en el mercado. Estos requieren naturalmente una observación mucho más intensa que aquellos bienes que hace largo tiempo se comercializan y respecto a los cuales no se han presentado hasta el momento incidentes o reclamos ${ }^{63}$.

\footnotetext{
${ }^{56}$ En este sentido FRISCH, Wolfgang, "Problemas fundamentales de la responsabilidad penal de los órganos de dirección de la empresa - Responsabilidad penal en el ámbito de la responsabilidad de la empresa y de la división del trabajo", en: MIR, Santiago; LUZÓN, Diego (Editores), Responsabilidad penal de las empresas y sus órganos y responsabilidad por el producto, Barcelona: Bosch, 1996, pp. 99-127, p. 113.

${ }^{57}$ Tribunal Supremo Federal alemán NJW 1994, 517, 519; FOERSTE, “§ 24. Verkehrspflichten”, cit. nota $\mathrm{n}^{\circ} 37$, número marginal 293.

${ }^{58}$ Véanse arts. 218 y 219 del Reglamento del sistema nacional de control de los productos farmacéuticos de uso humano (Decreto 3 del Ministerio de Salud, publicado en el Diario Oficial el 25 de junio del 2011).

${ }^{59}$ El que respecto de determinadas creaciones de riesgo en materia de fabricación y comercialización de productos no exista un programa positivizado específico de reducción de los mismos, no significa que sobre el fabricante no pesen deberes para la protección de bienes jurídicos. Y es que existen consideraciones de índole material que permite fundar tales deberes, más allá de su positivización. Al respecto véase supra 2.

${ }^{60}$ Así MICHALSKI, "Produktbeobachtung", cit. nota nº 52, p. 963.

${ }^{61}$ Tribunal Supremo Federal alemán NJW 1990, 906, 907 s.; BODEWIG, Der Rückruf, cit. nota n 49, p. 233; HOLTERMANN, Neue Lösungsansätze, cit. nota $\mathrm{n}^{\circ}$ 53, p. 39; MICHALSKI, "Produktbeobachtung", cit. nota $\mathrm{n}^{\circ} 52$, p. 963.

${ }^{62}$ HAGER, "§ 823”, cit. nota n 37, número marginal F 21; HOLTERMANN, Neue Lösungsansätze, cit. nota $\mathrm{n}^{\circ} 53$, p. 39.

${ }^{63}$ Así RETTENBECK, Stephan, Die Rückrufpflicht in der Produkthaftung - Zugleich ein Beitrag zur EGRichtlinie über die allgemeine Produktsicherheit vom 29. Juni 1992, Baden-Baden: Nomos, 1994, p. 23; cfr. también BODEWIG, Der Rückruf, cit. nota n 49, p. 233.
} 
CONTRERAS, Lautaro. "La responsabilidad penal del fabricante por la infracción de sus deberes de vigilancia, advertencia y retirada".

Si en el marco de la vigilancia del producto el fabricante constata que este representa un peligro para la vida o salud del consumidor no tolerado jurídicamente ${ }^{64}$, está obligado a adoptar las correspondientes medidas de evitación de riesgos. Aquí entran en consideración la advertencia y la retirada del producto del mercado ${ }^{65}$.

Así, el fabricante está obligado a advertir de los peligros del producto a las personas que lo hayan adquirido (no sólo a consumidores, sino a todos los actores relevantes en la cadena de distribución), entregando la información necesaria a través de cartas, correos electrónicos, inserciones en la prensa, etc. ${ }^{66}$. Dado el caso, el fabricante deberá comunicar al público métodos apropiados para evitar el peligro, a través de la observancia de modalidades de uso particulares. Cuando el producto represente un riesgo especialmente importante, pesará sobre el fabricante la obligación de retirarlo del mercado. La retirada de un producto del mercado consiste en la eliminación del riesgo que este conlleva a través de una reparación gratuita, el cambio por otro producto exento de defectos o la devolución de aquel a cambio de reintegrar el precio ${ }^{67}$. Aquí se trata de medidas mucho más intensas que la mera advertencia.

\subsection{La exigencia de una mera advertencia o bien de la retirada del producto en el caso concreto: orientaciones que entrega el principio de proporcionalidad.}

Surge inevitablemente la pregunta de si en el caso concreto el fabricante debe evitar el riesgo del producto a través de una simple advertencia al consumidor, o bien está obligado al retiro. Esto puede responderse con la ayuda de los principios constitucionales de necesidad y proporcionalidad en sentido estricto ${ }^{68}$. En efecto, como la simple advertencia

${ }^{64}$ Un producto representará un peligro no tolerado jurídicamente si un consumidor razonable - de conocer en detalle los riesgos del producto- evitaría el contacto con el mismo para así no afectar su vida o salud (CONTRERAS, Normative Kriterien, cit. nota ${ }^{\circ}$ 8, p. 201 s., 212; acerca de que el individuo no debe crear aquellos riesgos a los que una persona sensata no se expondría cfr. FRISCH, Tatbestandsmäßiges Verhalten, cit. nota ${ }^{\circ} 13$, p. 128 s., 138 s. Una argumentación similar a esta se puede encontrar en la sentencia del caso de la Colza (sentencia del Tribunal Supremo del 23.04.1992, publicada en ARJ 1992, N. ${ }^{\circ} 6783,8827,8875$ ), según la cual las exigencias de cuidado en el ámbito de fabricación de productos -y, con ello, los límites entre el riesgo tolerado y no tolerado que crea la conducta del fabricante- se determinan conforme a aquellos peligros que un consumidor estaría dispuesto a asumir a través de una ponderación de intereses razonable.

${ }^{65} \mathrm{La}$ información recabada por el fabricante en el marco de la vigilancia del producto también podría fundar, por ejemplo, la obligación de paralizar la producción en curso, modificar el diseño del bien de consumo o cambiar el proceso productivo.

${ }^{66}$ Un catálogo detallado acerca de los mecanismos posibles de comunicación de la advertencia se halla en el documento "Alertas y retiro voluntario de productos - Guía de proveedores", págs. 8 y 9 , elaborado por el SERNAC (en: http://www.seguridaddeproductos.cl/wp-content/uploads/2013/04/Gu\%C3\%ADa-deProveedores_Alertas-y-Retiros.pdf [visitado el 29.09.2014]).

${ }^{67}$ En este sentido HAGER, “\$ 823”, cit. nota n ${ }^{\circ} 37$, número marginal F 25.

${ }^{68}$ El que el principio de proporcionalidad constitucional (sobre su consagración en el Derecho Chileno véase NOGUEIRA, Humberto, Dogmática Constitucional, Talca: Editorial Universidad de Talca, 1997, p. 184-190) no sólo permita comprobar la legitimidad de los deberes jurídicos del fabricante (en tanto estos suponen una restricción -a lo menos- de la libertad de actuación general garantizada constitucionalmente, lo que requiere legitimación constitucional), sino también concretar tales deberes, es una opinión extendida hoy en el Derecho Civil (BECK, Thomas, Die präventive Durchsetzung der Rückrufpflicht - Möglichkeiten zur Erzwingung eines Produkterückrufs, Tübingen: Köhler, 2002, p. 22; BODEWIG, Der Rückruf, cit. nota n 49 , p. 210; MICHALSKI, "Produktbeobachtung", cit. nota n 52 , p. 964 s.; RETTENBECK, Die Rückrufpflicht, cit. nota $\mathrm{n}^{\circ}$ 63, p. 66) y Penal (BGHSt 37, 106, 121 ss.; HOLTERMANN, Neue Lösungsansätze, cit. nota ${ }^{\circ}$ 
Polit. crim. Vol. 10, № 19 (Julio 2015), Art. 9, pp. 266-296.

[http://www.politicacriminal.cl/Vol_10/n_19/Vol10N19A9.pdf]

supone una inversión (en tiempo, recursos humanos y materiales) mucho menor para el fabricante en comparación con la retirada y, consecuentemente, representa un medio menos gravoso para sus derechos fundamentales ${ }^{69}$, la imposición de un deber de retirada sólo se puede legitimar cuando la protección efectiva de los bienes jurídicos de los consumidores no se pueda alcanzar en el caso concreto a través de una mera advertencia a los consumidores (necesidad $)^{70}$. Pero además, siempre será necesario que las afectaciones a los derechos del fabricante, que conlleva la imposición del deber de retirada, no sean más gravosas que la necesidad de protección de los bienes del consumidor que persigue tal deber (proporcionalidad en sentido estricto) ${ }^{71}$.

De esta manera, si el riesgo del producto no se debe a una característica del mismo sino a una forma de uso peligrosa respecto a la cual no se advirtió en absoluto al momento de la introducción en el mercado, o se advirtió de un modo incorrecto, el Derecho sólo puede exigir (legítimamente) al productor que éste realice la advertencia posterior del caso ${ }^{72}$. Aquí no es necesaria una acción de retirada para la protección de los bienes del consumidor ${ }^{73}$. A modo ejemplar: un fabricante de maquinaria se percata que el uso de uno de sus productos genera determinados riesgos cuando se le combina con otros artefactos, que han sido comercializados recientemente por otra empresa. Como en este caso la omisión inicial de informar acerca de los peligros del uso conjunto de los productos se podría corregir a través de una advertencia posterior, el bien en cuestión no necesitaría ser retirado del mercado para proteger los intereses del consumidor.

A otra solución debe llegarse si el riesgo del producto no proviene de la falta o defecto de las instrucciones al consumidor sino de errores de diseño o fabricación. En consideración a los elevados riesgos para los bienes jurídicos de los consumidores que suponen tales errores del producto, es necesario adoptar medidas de evitación especialmente eficaces ${ }^{74}$. En consecuencia, el fabricante está obligado a retirar el producto del mercado. La ejecución de una acción de retirada, con los significativos costos económicos que trae consigo, es mucho más idónea que una simple advertencia para llamar la atención al consumidor acerca de la real peligrosidad del bien y, consiguientemente, para evitar que lo siga utilizando ${ }^{75}$. La retirada del producto es especialmente necesaria tratándose de productos caros, cuyo reemplazo o reparación el consumidor no puede financiar por sí mismo. En estos casos no

53, p. 39; KUHLEN, Lothar, "Die Pflicht zum Rückruf in der strafrechtlichen Produkthaftung", en: ARNOLD, Jörg [Editor], Menschengerechtes Strafrecht - Festschrift für Albin Eser zum 70. Geburtstag, München: C. H. Beck, 2005, pp. 359-372, pp. 362 y ss.; MAYER, Strafrechtliche Produktverantwortung, cit. nota $\mathrm{n}^{\circ} 3$, pp. 294, 297) alemán.

${ }^{69}$ En este sentido RETTENBECK, Die Rückrufpflicht, cit. nota n ${ }^{\circ}$ 63, p. 69.

${ }^{70} \mathrm{Cfr}$. al respecto Tribunal Constitucional Federal alemán, BVerfGE 38, 281, 302; 49, 24, 58; 113, $29,53 \mathrm{~s}$.

${ }^{71}$ Cfr. al respecto DOMEIER, Gesundheitsschutz, cit. nota n ${ }^{\circ} 6$, pp. 99, 136.

${ }^{72}$ Así MAYER, Strafrechtliche Produktverantwortung, cit. nota n ${ }^{\circ} 3$, p. 303; cfr. también BODEWIG, Der Rückruf, cit. nota n ${ }^{\circ} 49$, p. 261.

${ }^{73}$ Cfr. sobre esto Tribunal Supremo Federal alemán, NJW 1986, 1863, 1864; MICHALSKI, "Produktbeobachtung", cit. nota $\mathrm{n}^{\circ}$ 52, p. 965.

${ }^{74}$ Véase BODEWIG, Der Rückruf, cit. nota ${ }^{\circ}$ 49, p. 260; MICHALSKI, "Produktbeobachtung", cit. nota $n^{\circ}$ 52, p. 965; RETTENBECK, Die Rückrufpflicht, cit. nota n ${ }^{\circ} 63$, p. 71.

${ }^{75}$ Así RETTENBECK, Die Rückrufpflicht, cit. nota ${ }^{\circ}$ 63, p. 71; de acuerdo con él MAYER, Strafrechtliche Produktverantwortung, cit. nota ${ }^{\circ}$ 3, p. 296; en contra FOERSTE, “\$ 24. Verkehrspflichten", cit. nota n $^{\circ} 37$, número marginal 262. 
CONTRERAS, Lautaro. "La responsabilidad penal del fabricante por la infracción de sus deberes de vigilancia, advertencia y retirada".

se puede descartar que el usuario, pese a una (mera) advertencia, se incline a seguir utilizando el bien ${ }^{76}$.

Por otra parte, tratándose de riesgos del producto que afecten a niños, es necesaria por regla general una acción de retirada, no bastando una simple advertencia ${ }^{77}$. Los niños pueden no entender una advertencia o no ser capaces de implementarla ${ }^{78}$ A ello se debe agregar que, en atención a la curiosidad y tendencia a la experimentación propia de su edad, la advertencia puede ser más bien un estímulo para la utilización peligrosa del producto ${ }^{79}$.

En tanto la imposición del deber de retirada afecta derechos fundamentales (al menos, la libertad general de actuación del fabricante), es indispensable que este mandato cumpla también con la exigencia de proporcionalidad en sentido estricto. Ello significa que la afectación a la libertad del fabricante, que es consecuencia de la imposición del deber, no pese más que la necesidad de protección de los intereses del consumidor ${ }^{80}$. Este requisito sólo se cumplirá cuando - ponderando todos los intereses en juego- resulte un "saldo positivo" en favor de la imposición del deber ${ }^{81}$. Sólo así el deber de retirada será manifestación de un proceso de valoración jurídica correcto y podrá ser reconocido como norma de conducta legítima por los fabricantes, lo que es absolutamente indispensable -por lo demás- para su cumplimiento en la práctica ${ }^{82}$. En la balanza del juicio de ponderación deberán considerarse todos los gastos que supone para el fabricante la ejecución de una acción de retirada ${ }^{83}$, la eventual disminución de sus ventas, así como el posible menoscabo

${ }^{76}$ HERRMANN, Harald, "Die Rückrufhaftung des Produzenten”, BB 1985, pp. 1801-1812, p. 1806; RETTENBECK, Die Rückrufpflicht, cit. nota $\mathrm{n}^{\circ}$ 63, p. 71. Tratándose de las acciones de simple advertencia (pero también tratándose de acciones de retirada) se pueden suscitar problemas de imputación objetiva en sentido estricto, es decir, de realización del riesgo en el resultado. Y es que en los casos de responsabilidad penal por el producto se presentan una serie de circunstancias que podrán arrojar la duda de si acaso una advertencia o retirada del fabricante habría excluido o no el resultado con una probabilidad rayana en la certeza. Por ejemplo: siempre existe la posibilidad de que un consumidor haga caso omiso a una acción de retirada y siga empleando el bien, produciéndose un daño a su vida o salud. En tales casos ¿el resultado es obra del fabricante o del azar? Se trata de un problema que escapa a los objetivos de este trabajo. Aquí sólo cabe señalar que, dependiendo de las particularidades del caso concreto, podrá ofrecer alguna solución a este problema la teoría del incremento del riesgo (sobre la misma véase en detalle con ulteriores referencias KÜHL, Kristian, Strafrecht, Allgemeiner Teil, $7^{\text {a }}$ edición, München: Vahlen, 2012, § 7, número marginal 51) o los planteamientos que parten de la base de la autorresponsabilidad del consumidor, presumiéndose entonces que si este hubiera sido advertido o informado por el fabricante habría acatado su indicación, evitándose el resultado (cfr. EICHINGER, Die strafrechtliche Produkthaftung, cit. nota $\mathrm{n}^{\circ}$ 5, p. 201).

${ }^{77}$ Así BECK, Die präventive Durchsetzung, cit. nota n ${ }^{\circ} 68$, p. 24; BODEWIG, Der Rückruf, cit. nota $n^{\circ} 49$, pp. 228, 262.

${ }_{78}^{78}$ En este sentido expresamente BODEWIG, Der Rückruf, cit. nota n ${ }^{\circ}$ 49, p. 228.

${ }^{79}$ Cfr. en este sentido BODEWIG, Der Rückruf, cit. nota ${ }^{\circ} 49$, p. 228. Sobre la inconveniencia en algunos casos de advertir sobre los riesgos de un producto porque ello podría servir de estímulo para un mal uso del bien de consumo véase Tribunal Superior Federal alemán, NJW 1981, 2514, 2516; Tribunal Regional Superior de Karlsruhe NJW-RR 2001, 1174; BODEWIG, Der Rückruf, cit. nota n 49, p. 252.

${ }^{80}$ Cfr. al respecto DOMEIER, Gesundheitsschutz, cit. nota n ${ }^{\circ}$ 6, pp. 99, 136.

${ }^{81}$ Véase FREUND, Allgemeiner Teil, cit. nota ${ }^{\circ} 7, \S 1$, número marginal 20.

${ }^{82}$ Cfr. FREUND, Georg, "Richtiges Entscheiden - am Beispiel der Verhaltensbewertung aus der Perspektive des Betroffenen, insbesondere im Strafrecht Zugleich ein Beitrag zur Relativität objektiver Daten”, GA 1991, pp. 387-410, p. 396; FREUND, Allgemeiner Teil, cit. nota n $^{\circ}$ 7, § 1, número marginal 20.

${ }^{83}$ En todo caso, la sola circunstancia que la acción de retirada exija incurrir en grandes gastos, no es siempre excusa frente al Derecho para no llevarla a cabo. Quien ejerce una actividad que lleva aparejada la creación de 
Polít. crim. Vol. 10, № 19 (Julio 2015), Art. 9, pp. 266-296.

[http://www.politicacriminal.cl/Vol_10/n_19/Vol10N19A9.pdf]

en su prestigio ${ }^{84}$. Generalmente estos no serán factores que tengan preferencia por sobre los intereses relativos a la mantención de los bienes jurídicos vida y salud del consumidor ${ }^{85}$. Luego, el deber de retirada sólo podrá estimarse como desproporcionado cuando, por una parte, su cumplimiento ponga en peligro la subsistencia económica de la empresa y, por otra, las afectaciones a la salud que están en juego sean muy poco significativas (por ejemplo, ligeros malestares estomacales de los consumidores) ${ }^{86}$.

\subsection{Tratamiento de los deberes de vigilancia, advertencia y retirada conforme a los principios de los delitos de omisión.}

La infracción de los deberes de vigilancia, advertencia y retirada ya referidos son tratados en el Derecho Penal alemán ${ }^{87}$ y español ${ }^{88}$ conforme a los principios que rigen los delitos de omisión. De especial interés en esta materia resulta el razonamiento utilizado por el Tribunal Supremo Federal alemán en el conocido caso del "spray de cuero". Para distinguir entre conductas activas y omisivas del fabricante el tribunal utilizó el denominado "modelo de imputación de dos niveles" $" 89$. En un primer nivel (el verdaderamente decisivo para calificar la conducta como activa u omisiva) el tribunal se preguntó si el resultado debía reconducirse a la actividad o bien a la inactividad de la empresa de la cual los acusados eran directivos. Así, aquellas lesiones provocadas por la introducción en el mercado del producto defectuoso - por parte de "la empresa"- debían calificarse como delitos de acción. Por el contrario, aquellas lesiones causadas por la no retirada de los productos del mercado debían ser consideradas como delitos omisivos ${ }^{90}$. Para el tribunal lo decisivo fue si la "conducta" de la empresa se había manifestado en el mundo exterior como un hacer

riesgos para los bienes de los demás es responsable de contar con los medios materiales necesarios para su mitigación (cfr. RETTENBECK, Die Rückrufpflicht, cit. nota ${ }^{\circ}$ 63, p. 92). Dentro de estos riesgos se cuentan aquellos defectos del producto que incluso un fabricante diligente no es capaz de advertir al momento de introducir el bien en el mercado.

${ }^{84}$ Cfr. SCHMUCKER, Die „Dogmatik“, cit. nota ${ }^{\circ}$ 5, p. 156.

${ }^{85}$ Tribunal Supremo Federal alemán BGHSt 37, 106, 122; BECK, Die präventive Durchsetzung, cit. nota ${ }^{\circ}$ 68, p. 26; BOCK, Barbara, Produktkriminalität und Unterlassen, Aachen: Shaker, 1997, p. 148; GOLL, Eberhard; WINKELBAUER, Wolfgang, "§ 47. Materielle Voraussetzungen der strafrechtlichen Verantwortung für fehlerhafte Produkte”, en: GRAF V. WESTPHALEN, Friedrich (Editor), Produkthaftungshandbuch, Tomo 1, 2ª edición, München: C. H. Beck, 1997, número marginal 28.

${ }^{86}$ En este sentido Tribunal Supremo Federal alemán BGHSt 37, 106, 122; de acuerdo con este fallo BOCK, Produktkriminalität, cit. nota $n^{\circ}$ 85, p. 148 s.; GOLL, “\$ 47. Materielle Voraussetzungen”, cit. nota $n^{\circ} 85$, número marginal 28; MAYER, Strafrechtliche Produktverantwortung, cit. nota $n^{\circ}$ 3, p. 305.

${ }^{87}$ Cfr. Tribunal Supremo Federal alemán BGHSt 37, 106, 114; HÖHFELD, Strafrechtliche Produktverantwortung, cit. nota $\mathrm{n}^{\circ}$ 5, p. 13; MAYER, Strafrechtliche Produktverantwortung, cit. nota $\mathrm{n}^{\circ} 3$, p. 339.

${ }^{88}$ Para el Derecho español véase CUADRADO, María, La responsabilidad por omisión de los deberes del empresario - Análisis crítico del art. 363 del Código Penal, Barcelona: Bosch, 1998, p. 188 s.; JUANATEY, Carmen, "Responsabilidad penal omisiva del fabricante o productor por los daños a la salud derivados de productos introducidos correctamente en el mercado", Anuario de Derecho Penal y Ciencias Penales 2004, pp. 53-75, p. 53 s.; PEÑARANDA, Enrique, "Sobre la responsabilidad en comisión por omisión respecto de hechos cometidos en la empresa (y en otras organizaciones)", en: DÍAZ-MAROTO Y VILLAREJO, Julio (Editor), Liber amicorum en homenaje al profesor Antonio González-Cuéllar García, Madrid: Colex, 2006, pp. 411-430, p. 414.

${ }^{89}$ Expresión utilizado por WEI $\beta$, Holger, Die rechtliche Gewährleistung der Produktsicherheit, BadenBaden: Nomos, 2008, p. 512.

${ }^{90}$ Cfr. Tribunal Supremo Federal alemán BGHSt 37, 106, 114. 
CONTRERAS, Lautaro. "La responsabilidad penal del fabricante por la infracción de sus deberes de vigilancia, advertencia y retirada".

positivo (comercialización del producto) o un no hacer (omisión de la retirada) ${ }^{91}$. Irrelevante fue si, por ejemplo, en la reunión de crisis donde se decidió no retirar el producto del mercado los acusados se comportaron (como personas naturales) en forma activa o pasiva, es decir, expresaron opiniones o votaron en contra de la retirada, o bien guardaron silencio. De este modo, para la delimitación entre acción u omisión en materia de responsabilidad por el producto el tribunal trató ficticiamente a la organización empresarial como si fuera una verdadera persona natural ${ }^{92}$, capaz de poner en curso el suceso causal imprimiendo energía a su actuar o bien "dejar las cosas pasar"93. Recién en un segundo nivel, se imputó como propia la conducta de la empresa a los ejecutivos ${ }^{94}$, en función de la posición directiva que ocupaban en la organización. Al ocupar el nivel jerárquico más alto en la empresa, los ejecutivos eran precisamente los responsables de ordenar la retirada del producto $^{95}$. En este "modelo de imputación de dos niveles", el Tribunal Supremo alemán trató entonces la decisión de los acusados de no retirar un producto del mercado como una conducta omisiva. La doctrina, por su parte, también ha calificado como omisión la no advertencia o vigilancia de un bien de consumo ${ }^{96}$.

Ahora bien, al no existir en la legislación chilena tipos penales de omisión que castiguen como tal la no ejecución de acciones de vigilancia, advertencia o retirada, la sanción penal de estas conductas sólo podrá fundarse en la no evitación de un resultado de muerte (art. $391 \mathrm{~N}^{\circ} 2 \mathrm{CP}$ ) o lesiones (art. 399) ${ }^{97}$ del consumidor. Es decir, respecto de tales conductas sólo cabrá el castigo por la vía de los delitos de comisión por omisión. La existencia de una posición de garante del fabricante - requisito indispensable para el castigo de cualquier conducta a través de un delito de comisión por omisión- no se controvierte seriamente en la doctrina alemana. Discrepancias pueden encontrarse solamente en relación a cuál sería el concreto fundamento de tal posición. Así, para algunos aquél se halla en la circunstancia de que, al poner su producto en el mercado, el fabricante crea una fuente de peligro, la que

${ }^{91}$ KUHLEN, Lothar, “Grundfragen der strafrechtlichen Produkthaftung”, JZ 1994, pp. 1142-1147, p. 1144.

${ }^{92}$ Cfr. HÖHFELD, Strafrechtliche Produktverantwortung, cit. nota ${ }^{\circ}$ 5, p. 15; KUHLEN, "Grundfragen”, cit. nota $\mathrm{n}^{\circ} 91$, p. 1144 .

${ }^{93} \mathrm{Si}$ bien es cierto esta argumentación del Tribunal Supremo Federal alemán en el caso Lederspray ha sido muy criticada por la doctrina, pues con ella se estaría aceptando una capacidad de actuación de las personas jurídicas (ver en este sentido SCHÜNEMANN, Bernd, "Unternehmenskriminalität", en: ROXIN, Claus; WIDMAIER, Gunther (Editores), 50 Jahre Bundesgerichtshof, Festgabe aus der Wissenschaft, Tomo 4, München: C. H. Beck, 2000, pp. 621-646, p. 623), lo cierto es que prevalece la idea en la literatura científica alemana de que la falta de vigilancia de un producto, la no advertencia de sus peligros o la no retirada, debe tratarse conforme a los principios que rigen los delitos de omisión.

${ }^{94}$ Cfr. Tribunal Supremo Federal alemán BGHSt 37, 106, 114.

${ }^{95}$ Cfr. HEINE, Günter, Die strafrechtliche Verantwortlichkeit von Unternehmen - Von individuellem Fehlverhalten zu kollektiven Fehlentwicklung, insbesondere bei Großrisiken, Baden-Baden: Nomos, 1995, p. 156; HÖHFELD, Strafrechtliche Produktverantwortung, cit. nota $\mathrm{n}^{\circ}$ 5, p. 15; ROTSCH, Thomas, "Unternehmen, Umwelt und Strafrecht - Ätiologie einer Misere”, wistra 1999, pp. 321-327, p. 325.

${ }^{96}$ En este sentido HÖHFELD, Strafrechtliche Produktverantwortung, cit. nota ${ }^{\circ}$ 5, p. 13; MAYER, Strafrechtliche Produktverantwortung, cit. nota $\mathrm{n}^{\circ} 3$, p. 339.

${ }^{97}$ Como el art. 397 CP limita el castigo de las lesiones a aquellas que se provoquen (sólo) a través de las conductas de herir, golpear o maltratar, es difícilmente sostenible la posibilidad de sancionar en virtud de ese artículo la conducta del fabricante de no retirar del mercado un producto defectuoso. Lo mismo puede decirse en relación al tipo penal del art. $395 \mathrm{CP}$, que emplea la voz "castrare", y al delito del $398 \mathrm{CP}$, que utiliza el término "administrándole", conceptos que parecen excluir una conducta omisiva del fabricante. 
Polít. crim. Vol. 10, № 19 (Julio 2015), Art. 9, pp. 266-296.

[http://www.politicacriminal.cl/Vol_10/n_19/Vol10N19A9.pdf]

domina en atención a las posibilidades de control sobre el bien de consumo ${ }^{98}$. Otros autores vinculan la posición de garante con los deberes de aseguramiento del tráfico del Derecho Civil $^{99}$. Otros, finalmente, ven en la fabricación y comercialización de productos de consumo una conducta que constituye un riesgo especial o incrementado, por lo cual se podría renunciar en la injerencia al requisito de que la conducta previa sea contraria a deber $^{100}$.

En realidad, el fundamento de la posición de garante no tiene por qué ser distinto a los criterios materiales que legitiman cualquier deber de conducta del productor, y que ya hemos desarrollado en detalle (supra 2). Por eso, el fundamento de tal posición debe encontrarse en la consecuencia forzosa del reconocimiento de la libertad al fabricante, en orden a comercializar productos cuya peligrosidad nunca puede excluirse del todo, ni siquiera después de que hayan sido puestos en el mercado ${ }^{101}$. El estimar al fabricante garante frente a los peligros que surgen del producto representa, por lo demás, una solución adecuada, pues es precisamente él quien recoge todos los reclamos en relación al bien y quien se encuentra en la mejor posición para llevar a cabo una acción de retirada exitosa ${ }^{102}$.

La sanción a la infracción a los deberes de vigilancia, advertencia y retirada recurriendo a los delitos de peligro de los arts. 313d, 314 o 315 (todos del CP) no es posible, atendida la formulación en términos activos de las conductas punibles previstas en estos preceptos, a saber: "fabricar", "expender", "envenenar", "infectar", "efectuar adulteraciones", "vender" o "distribuir". Así por lo demás lo declaró la Corte Suprema a propósito del "caso del alimento enteral" " La exigencia de lex stricta impide aquí el castigo de las conductas omisivas del fabricante. No vigilar los peligros de un producto, no advertirlos después de su comercialización o no retirar los productos del mercado, no equivale en ningún caso a fabricarlos, expenderlos, envenenarlos, etc. ${ }^{104}$. Afirmar que para que no se frustre la finalidad perseguida por los preceptos indicados (a saber: la protección frente a los peligros para la salud de los consumidores provenientes de bienes de consumo) es posible castigar

${ }^{98}$ Así BRAMMSEN, Joerg, "Strafrechtliche Rückrufpflichten bei fehlerhaften Produkten?”, GA 1993, pp. 97 120, p. 113 s.; WEIBER, Bettina, Kausalitäts- und Täterschaftsprobleme bei der strafrechtlichen Würdigung pflichtwidriger Kollegialentscheidungen, Berlin: Duncker \& Humblot, 1996, pp. 59 y ss., 64.

${ }_{99}$ Por ejemplo HASSEMER, Winfried, “Anmerkungen zu BGH, Urt. v. 06.07.1990 - 2 StR 549/89 (Mainz)”, JuS 1991, pp. 253-255, p. 254; HILGENDORF, Eric, Strafrechtliche Produzentenhaftung in der „Risikogesellschaft", Berlin: Duncker \& Humblot, 1993, p. 141.

${ }^{100}$ Véase BOCK, Produktkriminalität, cit. nota n ${ }^{\circ}$ 85, p. 137; FREUND, Erfolgsdelikt, cit. nota ${ }^{\circ}$ 7, pp. 217 ss., JAKOBS, Günther, Strafrecht, Allgemeiner Teil, $2^{\mathrm{a}}$ edición, Berlin: Walter de Gruyter, 1991, Sección 29, número marginal 39 y ss.

${ }^{101}$ Desde un punto de vista formal, la posición de garante del fabricante encuentra su fundamento (al menos por lo que respecta al deber de advertencia del fabricante) en el art. 46 de la Ley N. ${ }^{\circ} 19.496$ sobre protección de los derechos de los consumidores.

${ }^{102}$ Recientemente en este sentido MURMANN, Uwe, Grundkurs Strafrecht, $2^{\mathrm{a}}$ edición, München: C. H. Beck, 2013, § 29, número marginal 62.

${ }^{103}$ Cfr. considerando $23^{\circ}$ de la sentencia de la Corte Suprema recaída en el "caso del alimento enteral" (pronunciada el 27.12.2012 en causa ROL 6831-12): “(...) el análisis que el tribunal hace es correcto, en cuanto de cara a los verbos rectores del tipo en estudio, adulterar,' vender' y'distribuir, concluye que claramente ellos implican conductas activas no susceptibles de ser realizadas por omisión y luego se sostiene que atendido el hecho que ese precepto tampoco está construido en relación a un resultado, no es posible en relación a ese extremo, levantar la tesis de que sea cometido por omisión".

${ }^{104}$ Cfr. en el Derecho Penal alemán REUS, Das Recht in der Risikogesellschaft, cit. nota n 9, p. 170. 
CONTRERAS, Lautaro. "La responsabilidad penal del fabricante por la infracción de sus deberes de vigilancia, advertencia y retirada".

también las conductas omisivas del fabricante, representaría una interpretación analógica inadmisible de los tipos ${ }^{105}$.

\section{Determinación de las personas responsables dentro de la empresa del cumplimiento de los deberes de vigilancia, advertencia y retirada.}

En lo dicho hasta ahora se ha partido del supuesto de que el fabricante, sobre el que pesan los deberes de vigilancia, advertencia y retirada, es una persona natural. Casos de este tipo son teóricamente posibles, pero constituyen más bien la excepción. Normalmente los productos no se fabrican por personas individuales, sino por organizaciones, constituidas bajo la forma de sociedades.

En el Derecho Penal chileno las personas jurídicas no son responsables penalmente por los delitos aplicables a los casos de responsabilidad por el producto (esto es, delitos contra la salud pública del párrafo XIV del Título VI del Libro II del Código Penal, de homicidio y de lesiones) ${ }^{106}$. Ello no quiere decir que las actividades de producción de bienes que se desarrollan al "interior" de la persona jurídica queden al margen de la reacción penal: la imposibilidad de castigar penalmente a la persona jurídica significa, únicamente, que es necesario identificar dentro de la organización a aquellos de sus integrantes a quienes les compete cumplir con los deberes jurídicos establecidos para la protección de la vida y salud del consumidor ${ }^{107}$.

La pregunta relativa a quién dentro de la empresa fabricante tiene la obligación de cumplir con los deberes que persiguen evitar los cursos dañosos para los bienes de los consumidores es una cuestión de responsabilidad personal en el marco de estructuras de división del trabajo de carácter horizontal y vertical ${ }^{108}$. No a todos los miembros de la organización les incumbe evitar tales cursos dañosos. Así: al gerente de recursos humanos de una empresa de productos lácteos no le compete asegurarse que en el marco del proceso de fabricación de un yogur se efectúen las pruebas necesarias para excluir defectos de fabricación. En esta materia resulta básico reconocer distintos ámbitos de responsabilidad al interior de la

\footnotetext{
${ }^{105}$ Una interpretación analógica semejante puede encontrarse en CUADRADO, La responsabilidad por omisión, cit. nota $\mathrm{n}^{\circ}$ 88, pp. 187 y ss., a propósito del art. 363.2 del Código Penal español ("Serán castigados con la pena de [...] los productores, distribuidores o comerciantes que pongan en peligro la salud de los consumidores: [...] 2. Fabricando o vendiendo bebidas o comestibles destinados al consumo público y nocivos para la salud"). La autora afirma que esta norma persigue la protección de la salud pública. Para que este fin no se frustre es necesario interpretar de un modo no literal las expresiones "fabricando" o "vendiendo". Porque lo que en realidad el tipo penal prohibiría sería, según Cuadrado, la causación de un peligro (concreto) para el bien jurídico salud pública a través de bebidas o comestibles en mal estado. Tal causación podría realizarse por medios activos, pero también por medios omisivos cuando el fabricante, por ejemplo, no retira a tiempo del mercado los comestibles o bebidas. Esta interpretación del delito del art. 363.2 del Código Penal español, desarrollada por Cuadrado, viola la prohibición de analogía.

${ }^{106}$ Cfr. Art. $1^{\circ}$ de la Ley 20.393.

${ }^{107}$ Cfr. MAYER, Strafrechtliche Produktverantwortung, cit. nota $\mathrm{n}^{\circ}$ 3, p. 339; SCHMIDT-SALZER, Joachim, "Strafrechtliche Produktverantwortung - Das Lederspray-Urteil des BGH", NJW 1990, pp. 29662972, p. 2967.

${ }^{108}$ En este sentido WEI $\beta$, Die rechtliche Gewährleistung, cit. nota n ${ }^{\circ} 89$, p. 513.
} 
Polit. crim. Vol. 10, № 19 (Julio 2015), Art. 9, pp. 266-296.

[http://www.politicacriminal.cl/Vol_10/n_19/Vol10N19A9.pdf]

empresa $^{109}$. Las esferas de responsabilidad de los distintos miembros de la organización se determinan -especialmente- sobre la base de la posición de cada integrante dentro de la misma y de las áreas de tareas y funciones vinculadas a esa posición ${ }^{110}$. Cabe advertir, en todo caso, que la fijación de los miembros de la empresa responsables de evitar riesgos penalmente relevantes no constituye un problema exclusivo de la responsabilidad penal por el producto. Se trata de una cuestión general propia de todo el Derecho Penal de la Empresa $^{111}$. Así, por ejemplo, en el Derecho Penal alemán las dificultades propias de la delimitación de ámbitos de responsabilidad entre los miembros de la organización empresarial también se presentan en el contexto de la minimización de riesgos ambientales (parágrafos 324 y siguientes del Código Penal alemán) ${ }^{112}$.

Las obligaciones de vigilancia, advertencia y retirada sobre bienes de consumo defectuosos competen (originalmente) a los miembros de la empresa que detentan el poder de organización sobre la producción y sobre la distribución de dichos bienes ${ }^{113}$. En atención a la relevancia que la actividad de producción y de distribución de bienes tiene en una empresa fabricante, el poder de organización referido normalmente recaerá en una o varias personas que ocupen puestos directivos o ejecutivos (Gerente General, Gerente de Producción, Gerente de Ventas, etc.). Este poder de organización debe ser determinado desde un punto de vista formal, pero también fáctico ${ }^{114}$. En consecuencia, no sólo será garante el directivo a quien los estatutos sociales hayan entregado explícitamente facultades sobre la producción o distribución, sino también aquel que en los hechos ejerza un control sobre tales ámbitos ${ }^{115}$.

Es posible que quienes detenten el poder de organización sobre la producción y distribución de bienes deleguen los deberes de vigilancia, advertencia y retirada en mandos medios de la empresa $^{116}$. Tal delegación será especialmente frecuente en organizaciones de gran tamaño.

${ }^{109}$ WEI $\beta$, Die rechtliche Gewährleistung, cit. nota ${ }^{\circ} 89$, p. 513; ver al respecto también MAYER, Strafrechtliche Produktverantwortung, cit. nota $\mathrm{n}^{\circ}$ 3, p. $341 \mathrm{~s}$.

${ }^{110}$ MAYER, Strafrechtliche Produktverantwortung, cit. nota ${ }^{\circ} 3$, p. 429 con abundantes referencias.

${ }^{111}$ Así KUHLEN, Lothar, Fragen einer strafrechtlichen Produkthaftung, Heidelberg: Müller, 1989, p. 27.

112 Sobre el particular en detalle BUSCH, Ralf, Unternehmen und Umweltstrafrecht, Osnabrück: Rasch, 1997, pp. 291 y ss.

${ }^{113}$ En este sentido SCHUMANN, Heribert, "Responsabilidad individual en la gestión de empresas Observaciones sobre la Sentencia Erdal del Tribunal Supremo Federal alemán (BGH)”, en: MIR, Santiago; LUZÓN, Diego (Editores), Responsabilidad penal de las empresas y sus órganos y responsabilidad por el producto, Barcelona: Bosch, 1996, pp. 199-213, p. 209 y s. Los deberes de garante de advertencia y retirada no sólo corresponden a los miembros de una empresa dedicada a la fabricación, sino también podrían alcanzar a los directivos de una empresa distribuidora o comercializadora.

${ }^{114}$ SCHUMANN, "Responsabilidad individual”, cit. nota $\mathrm{n}^{\circ} 113$, p. 210.

${ }^{115}$ Cfr. GARCÍA, Percy, La responsabilidad penal del administrador de hecho de la empresa: criterios de imputación, Barcelona: Bosch, 1999, p. 193.

${ }^{116}$ Sobre la posibilidad de delegar deberes de garante véase STREE, Walter; BOSCH, Nikolaus, "Vorbem. zu den $\S \S 13$ ff.”, en: Schönke/Schröder, Strafgesetzbuch, Kommentar, 29a edición, München: C. H. Beck, 2014, número marginal 152. Específicamente sobre la delegación de deberes al interior de la empresa véase, por ejemplo, ALEXANDER, Die strafrechtliche Verantwortlichkeit, cit. nota $\mathrm{n}^{\circ}$ 6, p. 195; HEINE, Günter; RINGELMANN, Christoph, "Strafrecht und Qualitätssicherung", en: BAUER, Carl-Otto; GRAF V. WESTPHALEN, Friedrich (Editores), Das Recht zur Qualität, Die Rechtsgrundlagen der Qualitätsorganisation, Berlin: Springer, 1996, pp. 359-390, p. 379; HERNÁNDEZ, Héctor, “Apuntes sobre la 
CONTRERAS, Lautaro. "La responsabilidad penal del fabricante por la infracción de sus deberes de vigilancia, advertencia y retirada".

En procesos productivos cada vez más complejos, y que exigen conocimientos técnicos altamente especializados, pareciera ser imposible exigir a los ejecutivos que cumplan de un modo personal y directo todos los deberes vinculados con la fabricación de un bien ${ }^{117}$. En tal contexto, es perfectamente posible concebir incluso la creación de una unidad al interior de la empresa encargada específicamente de la vigilancia, advertencia y retirada de productos. Si la empresa reviste cierto tamaño y complejidad, el establecimiento de tal departamento puede ser incluso la única manera de proteger adecuadamente los bienes jurídicos de los consumidores.

Si los deberes de vigilancia, advertencia y retirada se han delegado, los directivos que detenten el poder de organización podrán confiar en que los miembros de la empresa que han asumido las respectivas tareas cumplirán con su labor adecuadamente ${ }^{118}$. Con todo, para que el principio de confianza opere como límite de la responsabilidad en favor de los directivos, es fundamental que estos cumplan con sus respectivos deberes de elección, instrucción, control e intervención ${ }^{119}$. En efecto, los directivos están obligados a delegar las labores de vigilancia, advertencia y retirada sólo en aquellas personas que, por sus conocimientos, experiencia y posición dentro de la empresa, estén en condiciones de cumplir adecuadamente con semejantes tareas ${ }^{120}$. Además, es indispensable instruir detalladamente acerca de cuáles son las funciones que serán delegadas y ejercer un control para cerciorarse de que las tareas que se han entregado se están ejecutando fielmente. No es necesario (ni tampoco exigible por el Derecho) ejercer una supervisión permanente, pues de lo contrario se afectaría el propio sentido de la división del trabajo ${ }^{121}$. Basta con realizar controles ocasionales. Si en el marco de los mismos los directivos advierten que el o los subordinados no cumplen correctamente con su función, poniendo en peligro los bienes jurídicos de los consumidores, aquellos están obligados a intervenir y adoptar las medidas necesarias para evitar los resultados lesivos ${ }^{122}$. Si los directivos no cumplen con sus deberes de elección, instrucción, control e intervención, podrán ser responsables junto con los subordinados de los daños a la vida y salud de los consumidores que se causen como consecuencia de una deficiente vigilancia, advertencia o retirada de un producto.

responsabilidad penal (imprudente) de los directivos de empresa“, Revista de Estudios de la Justicia $\mathrm{n}^{\circ} 10$ (2008), pp. 175-198, pp. 195 y ss.

${ }^{117}$ Cfr. Tribunal Regional Superior de Hamm NJW 1971, p. 817; ALEXANDER, Die strafrechtliche Verantwortlichkeit, cit. nota $\mathrm{n}^{\circ}$ 6, p. 196.

${ }^{118}$ Véase Tribunal Supremo Federal alemán, wistra 2000, 305, 307; BOSCH, Organisationsverschulden, cit. nota $\mathrm{n}^{\circ}$ 3, p. 387; RANSIEK, Andreas, Unternehmensstrafrecht, Strafrecht, Verfassungsrecht, Regelungsalternativen, Heidelberg: Müller, 1996, p. 41. Sobre el pricipio de confianza como límite de los deberes jurídicos que pesan sobre el directivo de empresa véase HERNÁNDEZ, "Apuntes", cit. nota n 116, p. $191 \mathrm{~s}$.

${ }^{119}$ Cfr. ALEXANDER, Die strafrechtliche Verantwortlichkeit, cit. nota n ${ }^{\circ}$ 6, pp. 200 y ss.; EICHINGER, Die strafrechtliche Produkthaftung, cit. nota $\mathrm{n}^{\circ}$ 5, p. 126 s.; MARAVER, Mario, El principio de confianza en Derecho Penal - Un estudio sobre la aplicación del principio de autorresponsabilidad en la teoría de la imputación objetiva, Madrid: Civitas 2009, pp. 140 y ss.

${ }_{120}$ HEINE, "Strafrecht und Qualitätssicherung", cit. nota ${ }^{\circ}$ 116, p. 380.

${ }^{121}$ Así SCHMIDT-SALZER, Joachim, Produkthaftung - Bd. I Strafrecht, $2^{\mathrm{a}}$ edición, Heidelberg: Recht und Wirtschaft, 1988, número marginal 1.222.

${ }^{122}$ Véase DREHER, Meinrad, "Die persönliche Verantwortlichkeit von Geschäftsleitern nach außen und die innergesellschaftliche Aufgabenteilung", ZGR 1992, pp. 22-63, p. 55; MAYER, Strafrechtliche Produktverantwortung, cit. nota ${ }^{\circ} 3$, pp. 425 y 459; SCHMIDT-SALZER, Produkthaftung, cit. nota $\mathrm{n}^{\circ} 121$, número marginal $1.226 \mathrm{~s}$. 
Polít. crim. Vol. 10, № 19 (Julio 2015), Art. 9, pp. 266-296.

[http://www.politicacriminal.cl/Vol_10/n_19/Vol10N19A9.pdf]

Si los deberes de vigilancia, advertencia y retirada, por el contrario, no se han delegado, entonces serán responsables de cumplirlos todos quienes detenten el poder de organización sobre la producción y sobre la distribución de los bienes, esto es, todo el cuerpo directivo o ejecutivo de la empresa ${ }^{123}$.

Finalmente, surge la pregunta relativa a qué es lo que deberá en concreto hacer el garante (sea este un directivo o bien un mando medio en quien se hayan delegado los deberes de garante) para evitar el resultado lesivo. La respuesta a este problema no puede desatender las directrices generales que impone la dogmática de la omisión impropia. En consecuencia, el garante deberá hacer lo que sea necesario en la situación concreta para evitar el resultado típico ${ }^{124}$. Por lo tanto, en algunos casos no bastará -por ejemplo- con que el directivo vote a favor de la retirada del producto del mercado, sino que será exigible, además, dar aviso a la autoridad administrativa, comunicar la situación al presidente del directorio, intervenir personalmente en el proceso productivo y de distribución, dictando las respectivas instrucciones, etc.

\section{Conclusiones}

a) La indagación acerca de los riesgos del producto no identificables al momento de ponerlo en el mercado, la advertencia de tales riesgos al público, así como la eventual retirada del bien de consumo, constituyen no sólo prácticas empresariales ya asentadas, sino deberes jurídicos, esto es, conductas exigidas por el Derecho.

b) La condición básica para reconocer al fabricante su derecho a desarrollar una actividad productiva consiste en que aquel no afecte los bienes jurídicos del consumidor. La afectación de estos bienes jurídicos no sólo puede acontecer cuando el fabricante infringe sus deberes de diseño, fabricación e instrucción, sino también cuando, luego de descubrir riesgos del producto no reconocibles al momento de su comercialización, permanece inactivo.

c) Para la respuesta a la pregunta relativa a si en el caso concreto el fabricante debe advertir de los riesgos del producto, o bien retirar este del mercado, la doctrina alemana ha recurrido al principio de proporcionalidad constitucional. De este modo, tal principio se ha erigido como una pauta en el proceso de concreción de lo que el Derecho puede exigir para la protección de bienes jurídicos.

d) Junto con el problema relativo a si en el caso concreto el fabricante debe simplemente advertir del riesgo o bien retirar un producto del mercado, surge la interrogante relativa a quién es el responsable al interior de la organización empresarial de cumplir tales mandatos. En esta materia resulta fundamental reconocer distintos ámbitos de responsabilidad, establecidos a partir de la distribución de labores que exista entre los miembros de la organización. Demás está decir que la cuestión relativa a quién o quiénes dentro de la empresa compete cumplir con normas de conducta destinadas a la

\footnotetext{
${ }^{123}$ SCHUMANN, "Responsabilidad individual”, cit. nota ${ }^{\circ} 113$, p. 212.

${ }^{124}$ Por todos véase ROXIN, Claus, Strafrecht, Allgemeiner Teil, Tomo 2, München: C. H. Beck, 2003, § 31, número marginal 180, con más referencias.
} 
CONTRERAS, Lautaro. "La responsabilidad penal del fabricante por la infracción de sus deberes de vigilancia, advertencia y retirada".

protección de bienes jurídicos, representa un problema no exclusivo de la responsabilidad penal por el producto, sino que también se manifiesta en otras ramas del Derecho Penal de la Empresa (Derecho Penal Ambiental, por ejemplo).

e) La infracción de los deberes jurídicos de vigilancia, advertencia y retirada hace necesaria la intervención del orden sancionatorio penal: estamos ante una puesta en tela de juicio de normas de conducta que protegen bienes jurídicos fundamentales y no parecieran existir medios menos gravosos e igualmente eficaces para la mantención de la vigencia de las respectivas normas de conducta. 
Polít. crim. Vol. 10, № 19 (Julio 2015), Art. 9, pp. 266-296.

[http://www.politicacriminal.cl/Vol_10/n_19/Vol10N19A9.pdf]

\section{BIBLIOGRAFÍA CITADA}

ALEXANDER, Thorsten, Die strafrechtliche Verantwortlichkeit für die Wahrung der Verkehrssicherungspflichten in Unternehmen, Herbolzheim: Centaurus, 2005.

APPEL, Ivo, Verfassung und Strafe - Zu den verfassungsrechtlichen Grenzen staatlichen Strafens, Berlin: Duncker \& Humblot, 1998.

BARROS, Enrique, Tratado de responsabilidad extracontractual, Santiago de Chile: Editorial Jurídica de Chile, 2013.

BECK, Thomas, Die präventive Durchsetzung der Rückrufpflicht - Möglichkeiten zur Erzwingung eines Produkterückrufs, Tübingen: Köhler, 2002.

BOCK, Barbara, Produktkriminalität und Unterlassen, Aachen: Shaker, 1997.

BODEWIG, Theo, Der Rückruf fehlerhafter Produkte - Eine Untersuchung der Rückrufpflichten und Rückrufansprüche nach dem Recht Deutschlands, der Europäischen Union und der USA, Tübingen: Mohr Siebeck, 1999.

BORER, Peter, Produktehaftung: Der Fehlerbegriff nach deutschem, amerikanischem und europäischem Recht, Bern: Haupt, 1986.

BOSCH, Nikolaus, Organisationsverschulden in Unternehmen, Baden-Baden: Nomos, 2002.

BUSCH, Ralf, Unternehmen und Umweltstrafrecht, Osnabrück: Rasch, 1997.

BRAMMSEN, Joerg, "Strafrechtliche Rückrufpflichten bei fehlerhaften Produkten?", GA 1993, pp. 97-120.

CONTRERAS, Lautaro, Normative Kriterien zur Bestimmung der Sorgfaltspfichten des Produzenten, Berlin: Duncker \& Humblot, 2012.

CORRAL, Hernán, Responsabilidad por productos defectuosos - Análisis y propuestas para el Derecho Civil y de Consumo en Chile, Santiago de Chile: Legal Publishing Chile, 2011.

CUADRADO, María, La responsabilidad por omisión de los deberes del empresario Análisis crítico del art. 363 del Código Penal, Barcelona: Bosch, 1998.

DANNECKER, Gerhard, "Fahrlässigkeit in formalen Organisationen", en: AMELUNG, Knut (Editor), Individuelle Verantwortung und Beteiligungsverhältnisse bei Straftaten in Bürokratischen Organisationen des Staates und der Gesellschaft, Sizheim: Pro-Universitate, 2000, pp. 209-237.

DOMEIER, Danja, Gesundheitsschutz und Lebensmittelstrafrecht, Frankfurt am Main: Peter Lang, 1999.

DREHER, Meinrad, "Die persönliche Verantwortlichkeit von Geschäftsleitern nach außen und die innergesellschaftliche Aufgabenteilung", ZGR 1992, pp. 22-63.

EICHINGER, Harald, Die strafrechtliche Produkthaftung im deutschen im Vergleich zum anglo-amerikanischen Recht, Frankfurt am Main: Peter Lang, 1997.

FOERSTE, Ulrich, “\$ 24. Verkehrspflichten im Bereich der Warenherstellung”, en: GRAF V. WESTPHALEN, Friedrich (Editor), Produkthaftungshandbuch, Tomo 1, $2^{\mathrm{a}}$ edición, München: C. H. Beck, 1997.

FREUND, Georg, "Richtiges Entscheiden - am Beispiel der Verhaltensbewertung aus der Perspektive des Betroffenen, insbesondere im Strafrecht Zugleich ein Beitrag zur Relativität objektiver Daten”, GA 1991, pp. 387-410. , Erfolgsdelikt und Unterlassen, Köln: Heymann, 1992. 
CONTRERAS, Lautaro. "La responsabilidad penal del fabricante por la infracción de sus deberes de vigilancia, advertencia y retirada".

, "Vorbem. zu den $\S \S 95$ ff. AMG”, en: JOECKS, Wolfgang; MIEBACH, Klaus (Editores), Münchener Kommentar zum Strafgesetzbuch, Tomo 5, München: C. H. Beck, 2007.

, Strafrecht, Allgemeiner Teil, $2^{a}$ edición, Berlin: Springer, 2009.

FRISCH, Wolfgang, Vorsatz und Risiko Grundfragen des tatbestandsmäßigen Verhaltens und des Vorsatzes - Zugleich ein Beitrag zur Behandlung außertatbestandlicher Möglichkeitsvorstelllungen, Köln: Carl Heymanns, 1983.

, Tatbestandsmäßiges Verhalten und Zurechnung des Erfolgs, Heidelberg: Müller, 1988.

, Verwaltungsakzessorietät und Tatbestandsverständnis im Umweltstrafrecht Zum Verhältnis von Umweltverwaltungsrecht und Strafrecht und zur strafrechtlichen Relevanz behördlicher Genehmigungen, Heidelberg: Müller, 1993.

, "Problemas fundamentales de la responsabilidad penal de los órganos de dirección de la empresa - Responsabilidad penal en el ámbito de la responsabilidad de la empresa y de la división del trabajo", en: MIR, Santiago; LUZÓN, Diego (Editores), Responsabilidad penal de las empresas y sus órganos y responsabilidad por el producto, Barcelona: Bosch, 1996, pp. 99-127.

, "Wesenszüge rechtswissenschaftlichen Arbeitens - am Beispiel und aus der Sicht des Strafrechts (Kommentar)", en: ENGEL, Christoph; SCHÖN, Wolfgang (Editores), Das Proprium der Rechtswissenschaft, Tübingen: Mohr Siebeck, 2007, pp. 156-184.

, "Notstandsregelungen als Ausdruck von Rechtsprinzipien", en: PAEFFGEN, Hans-Ullrich et al (Editores), Strafrechtswissenschaft als Analyse und Konstruktion Festschrift für Ingeborg Puppe zum 70. Geburtstag, Berlin: Duncker \& Humblot, 2011, pp. 425-450

GARCÍA, Percy, La responsabilidad penal del administrador de hecho de la empresa: criterios de imputación, Barcelona: Bosch, 1999.

GOLL, Eberhard; WINKELBAUER, Wolfgang, "§ 47. Materielle Voraussetzungen der strafrechtlichen Verantwortung für fehlerhafte Produkte", en: GRAF V. WESTPHALEN, Friedrich (Editor), Produkthaftungshandbuch, Tomo 1, 2a edición, München: C. H. Beck, 1997.

HABERMAS, Jürgen, Faktizität und Geltung - Beiträge zur Diskurstheorie des Rechts und des demokratischen Rechtsstaats, $2^{\mathrm{a}}$ edición, Frankfurt am Main: Suhrkamp, 1992.

HAGER, Johannes, “§ 823”, en: J. von StaudingersKommentar zum Bürgerlichen Gesetzbuch mit Einführungsgesetz und Nebengesetzen, Buch 2 Recht der Schuldverhältnisse $\$ \S 823$ E-I, 824, 825 (Unerlaubte Handlungen 1 - Teilband 2), Berlin: Sellier - de Gruyter, 2009.

HASSEMER, Winfried, “Anmerkungen zu BGH, Urt. v. 06.07.1990 - 2 StR 549/89 (Mainz)", JuS 1991, pp. 253-255.

HEINE, Günter, Die strafrechtliche Verantwortlichkeit von Unternehmen - Von individuellem Fehlverhalten zu kollektiven Fehlentwicklung, insbesondere bei Großrisiken, Baden-Baden: Nomos, 1995.

HEINE, Günter; RINGELMANN, Christoph, "Strafrecht und Qualitätssicherung", en: BAUER, Carl-Otto; GRAF V. WESTPHALEN, Friedrich (Editores), Das Recht zur 
Polit. crim. Vol. 10, № 19 (Julio 2015), Art. 9, pp. 266-296.

[http://www.politicacriminal.cl/Vol_10/n_19/Vol10N19A9.pdf]

Qualität, Die Rechtsgrundlagen der Qualitätsorganisation, Berlin: Springer, 1996, pp. 359-390.

HERNÁNDEZ, Héctor, "El problema de la causalidad general' en el derecho penal chileno (con ocasión del art. 232 del Anteproyecto de Nuevo Código Penal)", Polít. crim. $\mathrm{n}^{\circ}$ 1 (2006), A7, p. 1-33 en: http://www.politicacriminal.cl/n_01/pdf_01/a 7.pdf. (visitado el 03.09.2014).

"Apuntes sobre la responsabilidad penal (imprudente) de los directivos de empresa“, Revista de Estudios de la Justicia n 10 (2008), pp. 175-198.

HERRMANN, Harald, "Die Rückrufhaftung des Produzenten”, BB 1985, pp. 1801-1812.

HILGENDORF, Eric, Strafrechtliche Produzentenhaftung in der „Risikogesellschaft“, Berlin: Duncker \& Humblot, 1993.

, "Der gesetzmäßige Zusammenhang im Sinne der modernen Kausallehre", Jura 1995, pp. 514-522.

HÖHFELD, Hendrik, Strafrechtliche Produktverantwortung und Zivilrecht, Berlin: Springer, 1999.

HOLTERMANN, Christian, Neue Lösungsansätze zur strafrechtlichen Produkthaftung Eine Untersuchung unter Heranziehung des Tatbestandes der gemeingefährlichen Vergiftung - 314 Abs. 1 Nr. 2 StGB, Baden-Baden: Nomos, 2007.

HUFEN, Friedhelm, Verfassungsrechtliche Maßstäbe und Grenzen lebensmittelstrafrechtlicher Verantwortung - Zur Bestimmtheit, Differenziertheit und Verhältnismäßigkeit berufsregelnder Risikoverteilung, Baden-Baden: Nomos, 1987.

JAKOBS, Günther, Strafrecht, Allgemeiner Teil, 2ª edición, Berlin: Walter de Gruyter, 1991.

JUANATEY, Carmen, "Responsabilidad penal omisiva del fabricante o productor por los daños a la salud derivados de productos introducidos correctamente en el mercado", Anuario de Derecho Penal y Ciencias Penales 2004, pp. 53-75.

KAUFMANN, Armin, "Tatbestandsmäßigkeit und Verursachung im Contergan-Verfahren - Folgerungen für das geltende Recht und für die Gesetzgebung”, JZ 1971, pp. 569576.

KINDHÄUSER, Urs, Strafrecht, Allgemeiner Teil, 5a edición, Baden-Baden: Nomos, 2011.

KREMER-BAX, Alexandra, Das personale Verhaltensunrecht der Fahrlässigkeitstat Zur Individualisierung des Bewertungsgegenstands, Frankfurt am Main: Peter Lang, 1999.

KÜHL, Kristian, Strafrecht, Allgemeiner Teil, $7^{\text {a }}$ edición, München: Vahlen, 2012.

KUHLEN, Lothar, Fragen einer strafrechtlichen Produkthaftung, Heidelberg: Müller, 1989.

, "Grundfragen der strafrechtlichen Produkthaftung”, JZ 1994.

"Die Pflicht zum Rückruf in der strafrechtlichen Produkthaftung", en: ARNOLD, Jörg (Editor), Menschengerechtes Strafrecht - Festschrift für Albin Eser zum 70. Geburtstag, München: C. H. Beck, 2005, pp. 359-372.

LENCKNER, Theodor, "Technische Normen und Fahrlässigkeit", en: BOCKELMANN, Paul (Editor), Festschrift für Karl Engisch zum 70. Geburtstag, Frankfurt am Main: Klostermann, 1969, pp. 490-508.

MARAVER, Mario, El principio de confianza en Derecho Penal - Un estudio sobre la aplicación del principio de autorresponsabilidad en la teoría de la imputación objetiva, Madrid: Civitas, 2009. 
CONTRERAS, Lautaro. "La responsabilidad penal del fabricante por la infracción de sus deberes de vigilancia, advertencia y retirada".

MAYER, Michael, Strafrechtliche Produktverantwortung bei Arzneimittelschäden - Ein Beitrag zur Abgrenzung der Verantwortungsbereiche im Arzneiwesen aus strafrechtlicher Sicht, Berlin: Springer, 2008.

MICHALSKI, Lutz, "Produktbeobachtung und Rückrufpflicht des Produzenten", BB 1998, pp. 961-966.

MÜNZBERG, Wolfgang, Verhalten und Erfolg als Grundlagen der Rechtswidrigkeit und Haftung. Frankfurt am Main: Klostermann, 1966.

MURMANN, Uwe, Grundkurs Strafrecht, 2a edición, München: C. H. Beck, 2013.

NOGUEIRA, Humberto, Dogmática Constitucional, Talca: Editorial Universidad de Talca, 1997.

, "La libertad personal y las dos caras de Jano en el ordenamiento jurídico chileno", Revista de Derecho, Vol. XIII (2002), pp. 161-186.

PEÑARANDA, Enrique, "Sobre la responsabilidad en comisión por omisión respecto de hechos cometidos en la empresa (y en otras organizaciones)", en: DÍAZ-MAROTO Y VILLAREJO, Julio (Editor), Liber amicorum en homenaje al profesor Antonio González-Cuéllar García, Madrid: Colex, 2006, pp. 411-430.

PFEIFER, Axel, Produktfehler oder Fehlverhalten des Produzenten - Das neue Produkthaftungsrecht in Deutschland, den USA und nach der EG-Richtlinie, Berlin: Duncker \& Humblot, 1987.

PUPPE, Ingeborg, "Vorbemerkungenzu $§ \S 13$ ff”, en: KINDHÄUSER, Urs; NEUMANN, Ulfrid; PAEFFGEN, Hans-Ullrich (Editores), Nomos Kommentar, Strafgesetzbuch, Tomo 1, 4ª edición, Baden-Baden: Nomos, 2013.

RANSIEK, Andreas, Unternehmensstrafrecht, Strafrecht, Verfassungsrecht, Regelungsalternativen, Heidelberg: Müller, 1996.

RAWLS, John, Eine Theorie der Gerechtigkeit, Frankfurt am Main: Suhrkamp, 1975.

RENZIKOWSKI, Joachim, Restriktiver Täterbegriff und fahrlässige Beteiligung, Tübingen: Mohr Siebeck, 1997.

REUS, Katharina, Das Recht in der Risikogesellschaft - Der Beitrag des Strafrechts zum Schutz vor modernen Produktgefahren, Berlin: Duncker \& Humblot, 2010.

RETTENBECK, Stephan, Die Rückrufpflicht in der Produkthaftung - Zugleich ein Beitrag zur EG-Richtlinie über die allgemeine Produktsicherheit vom 29. Juni 1992, BadenBaden: Nomos, 1994.

ROJAS, Luis, "Accesoriedad del Derecho Penal", en: VAN WEEZEL, Alex (Editor), Humanizar y renovar el Derecho Penal, Estudios en memoria de Enrique Cury, Santiago: Legal Publishing, 2013, pp. 93-107.

ROTSCH, Thomas, "Unternehmen, Umwelt und Strafrecht - Ätiologie einer Misere", wistra 1999, pp. 321-327.

ROXIN, Claus, Strafrecht, Allgemeiner Teil, Tomo 2, München: C. H. Beck, 2003.

SALVADOR, Pablo; RAMOS, Sonia, "Capítulo IV. Defectos de producto", en: SALVADOR, Pablo; GÓMEZ, Fernando (Editores), Tratado de responsabilidad civil del fabricante, Cizur Menor: Aranzadi, 2008, pp. 135-219.

SCHMIDT-SALZER, Joachim, Produkthaftung - Bd. I Strafrecht, $2^{\text {a }}$ edición, Heidelberg: Recht und Wirtschaft, 1988.

, "Strafrechtliche Produktverantwortung - Das Lederspray-Urteil des BGH", NJW 1990, pp. 2966-2972. 
Polít. crim. Vol. 10, № 19 (Julio 2015), Art. 9, pp. 266-296.

[http://www.politicacriminal.cl/Vol_10/n_19/Vol10N19A9.pdf]

SCHMUCKER, Andrea, Die „Dogmatik“ einer strafrechtlichen Produktverantwortung, Frankfurt am Main: Peter Lang, 2001.

SCHUMANN, Heribert, "Responsabilidad individual en la gestión de empresas Observaciones sobre la Sentencia Erdal del Tribunal Supremo Federal alemán (BGH)”, en: MIR, Santiago; LUZÓN, Diego (Editores), Responsabilidad penal de las empresas y sus órganos y responsabilidad por el producto, Barcelona: Bosch, 1996, pp. 199-213.

SCHÜNEMANN, Bernd, "Unternehmenskriminalität", en: ROXIN, Claus; WIDMAIER, Gunther (Editores), 50 Jahre Bundesgerichtshof, Festgabe aus der Wissenschaft, Tomo 4, München: C. H. Beck, 2000, pp. 621-646,

SPINDLER, Gerald, “\$ 823”, en: BAMBERGER, Heinz Georg; ROTH, Herbert (Editores), Beck'scher Online-Kommentar BGB, 20ª Edición, München: C.H. Beck, 2011.

STREE, Walter; BOSCH, Nikolaus, "Vorbem. zu den $\S \S 13$ ff.", en: Schönke/Schröder, Strafgesetzbuch, Kommentar, 29a edición, München: C. H. Beck, 2014.

VOGEL, Joachim, "Verbraucherschutz durch strafrechtliche Produkthaftung Kriminologische und funktionale Aspekte", GA 1990, pp. 241-264.

WEI $\beta$, Holger, Die rechtliche Gewährleistung der Produktsicherheit, Baden-Baden: Nomos, 2008.

WEI $\beta E R$, Bettina, Kausalitäts- und Täterschaftsprobleme bei der strafrechtlichen Würdigung pflichtwidriger Kollegialentscheidungen, Berlin: Duncker \& Humblot, 1996.

WOHLERS, Wolfgang, Deliktstypen des Präventionsstrafrechts - Zur Dogmatik "moderner" Gefährdungsdelikte, Berlin: Duncker \& Humblot, 2000.

ZACZYK, Rainer, Das Unrecht der versuchten Tat, Berlin: Duncker \& Humblot, 1989.

ZIPPELIUS, Reinhold, Rechtsphilosophie, 6 edición, München: C. H. Beck, 2011. 